\title{
Crystal Structures and Mechanical Properties of Fe-Zn Intermetallic Compounds Formed in the Coating Layer of Galvannealed Steels
}

\author{
Haruyuki INUI, ${ }^{1,2) *}$ Norihiko L. OKAMOTO ${ }^{1,2,3)}$ and Shu YAMAGUCHI ${ }^{4)}$ \\ 1) Department of Materials Science and Engineering, Kyoto University, Sakyo-ku, Kyoto, 606-8501 Japan. \\ 2) Center for Elements Strategy Initiative for Structure Materials (ESISM), Kyoto University, Kyoto, 606-8501 Japan. \\ 3) Now at Institute for Materials Research, Tohoku University, Aoba-ku, Sendai, Miyagi, 980-8577 Japan. \\ 4) Department of Materials Engineering, The University of Tokyo, 7-3-1 Hongo, Bunkyo-ku, Tokyo, $113-8656$ Japan.
}

(Received on February 1, 2018; accepted on February 28, 2018; J-STAGE Advance published date: July 28,20181

\begin{abstract}
The crystal structures of all intermetallics of the Fe-Zn system have been investigated by synchrotron X-ray diffraction combined with atomic-resolution scanning transmission electron microscopy, in order to elucidate a basic principle based on which these crystal structures are constructed. The plastic deformation behavior of all these Fe-Zn intermetallics have also been investigated by micropillar compression testing at room temperature, with the use of small-scale pillar specimens of micrometer size, in order to elucidate operative slip systems and their critical resolved shear stress values. The observed deformation behavior is discussed in the light of the deduced building principle of the crystal structures.
\end{abstract}

KEY WORDS: crystal structure; icosahedron; plastic deformation; deformability; dislocation.

\section{Introduction}

Galvannealed (GA) steels, which have widely been used in the automobile industry, ${ }^{1-3)}$ are usually produced by hotdip galvanizing, in which steel strips are immersed into a molten zinc bath, followed by heat-treatment to form an intermetallic coating layer through thermal diffusion in the zinc coating and the substrate iron. The coating layer of GA steels usually consists of five intermetallic compounds, $\Gamma\left(\mathrm{Fe}_{4} \mathrm{Zn}_{9}\right), \Gamma_{1}\left(\mathrm{Fe}_{11} \mathrm{Zn}_{40}\right), \delta_{1 \mathrm{k}}\left(\mathrm{FeZn}_{7}\right), \delta_{\mathrm{lp}}\left(\mathrm{Fe}_{13} \mathrm{Zn}_{126}\right)$ and $\zeta$ $\left(\mathrm{FeZn}_{13}\right)$ phases in the decreasing order of the Fe content, according to the $\mathrm{Fe}-\mathrm{Zn}$ binary phase diagram (Fig. 1). ${ }^{4-11)}$ However, problems called powdering and flaking are known sometimes to occur in the steel forming process in the automobile industry. ${ }^{2}$ Powdering is known to occur by particle formation through intracoating failure when the annealing is made excessively so that the Fe content in the coating layer is high. This is usually ascribed to the brittleness of $\Gamma$ and $\Gamma_{1}$ phases. On the other hand, flaking is known to occur by the formation of flat particles through the decohesion of the coating-substrate interface when the annealing is made insufficiently so that the Fe content in the coating layer is low. This is usually ascribed also to the brittleness of $\Gamma$ and $\Gamma_{1}$ phases as well as the softness of the $\zeta$ phase. The intermediate annealing condition is thus usually used to prevent from powdering and flaking so that the main

\footnotetext{
* Corresponding author: E-mail: inui.haruyuki.3z@kyoto-u.ac.jp
} DOI: http://dx.doi.org/10.2355/isijinternational.ISIJINT-2018-066 constituent phases of the coating layer are $\delta_{1 \mathrm{k}}$ and $\delta_{\mathrm{lp}}$, and that the experience in the industry assumes that these two phases are the most ductile.

These problems called flaking and powdering cannot be solved without knowledge on the mechanical properties (deformation, elastic, fracture and so on) for each of the five intermetallic compounds ${ }^{1,8,9,12-23)}$ as well as their thermodynamic properties (phase diagram/relationships). ${ }^{4-7)}$ However, almost nothing is known about the physical and

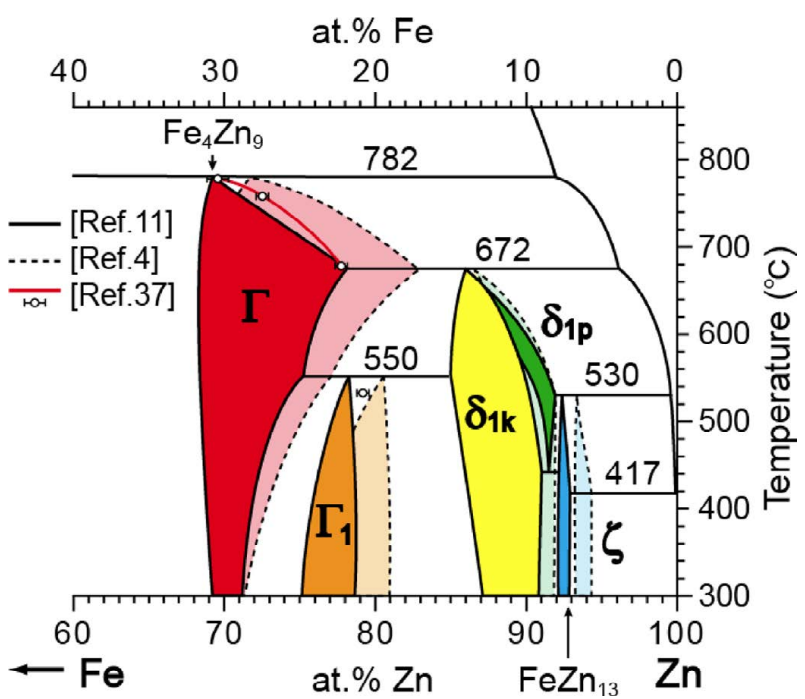

Fig. 1. Reported partial binary phase diagram in the Fe-Zn system. ${ }^{4,11,37)}$ (Online version in color.) 
mechanical properties of these intermetallic phases in the $\mathrm{Fe}-\mathrm{Zn}$ system. There is actually no direct evidence to indicate the brittleness or ductility for any of the phases of question. In this perspective, the crystal structure information for these intermetallics is fundamentally very important to consider elementary processes of plastic deformation such as slip planes, slip directions, dislocation Burgers vectors and dislocation dissociation. ${ }^{18,19,24,25)}$ The crystal structures of all the Fe-Zn intermetallics, except for that of the $\delta_{1 \mathrm{k}}$ phase, have long been investigated by X-ray diffraction in the past. ${ }^{26-34)}$ In general, all of them have a very complex crystal structures comprising coordinated polyhedra such as icosahedra. There seem some discrepancies in their reported crystal structures in terms of what kinds of polyhedra exist, how these polyhedra are linked to one another, and how $\mathrm{Fe}$ and $\mathrm{Zn}$ atoms occupy particular crystallographic sites of these polyhedra. ${ }^{26-34)}$ The complexity of the crystal structures as well as the small difference in the X-ray/electron scattering factors for $\mathrm{Fe}$ and $\mathrm{Zn}$ atoms may be one of the major reasons for the discrepancies. In addition, the difficulties in obtaining large-sized single crystals arising from the fact that all the phases are formed through a series of peritectic or peritectoid reactions ${ }^{4,11)}$ may be partly responsible for the discrepancies. However, we have recently shown that synchrotron X-ray diffraction (XRD) combined with atomicresolution scanning transmission electron microscopy (STEM) is very powerful in crystal structure refinement of the intermetallic of the $\delta_{\mathrm{lp}}$ phase., ${ }^{9,35)}$ We have applied this combined technique to crystal structure refinement of the other intermetallics of the Fe-Zn system, ${ }^{8,36,37)}$ in order to solve the discrepancies in their reported crystal structures; what kinds of polyhedra exist, how these polyhedra are linked to one another and how Fe and Zn atoms occupy particular crystallographic sites of these polyhedra. On the other hand, the plastic deformation behavior of any of these intermetallics of the $\mathrm{Fe}-\mathrm{Zn}$ system has never been explored in detail. This is due mainly to the difficulties in obtaining large-sized single and polycrystals of any single-phase by the reasons described above. On top of that, plastic flow is not believed to occur at ambient temperature for these intermetallics because of their very complex crystal structures. We have, however, recently shown that plastic flow occurs by slip deformation, at least, for two intermetallics, $\Gamma$ and $\zeta$, in compression for micrometer-sized specimens. ${ }^{18,38)}$ With the use of the micropillar compression testing method, we may be able to obtain fundamental knowledge about the strength and ductility at ambient temperature for each of the five $\mathrm{Fe}-\mathrm{Zn}$ intermetallics of the coating layer.

In the present paper, we review the results of our investigation on the crystal structures of all these intermetallics of the $\mathrm{Fe}-\mathrm{Zn}$ system by the above-mentioned combined technique, in order to elucidate a building principle of the crystal structures. We also review the results of our investigation on the plastic deformation behavior of each of these intermetallics in micropillar compression at ambient temperature, so that the observed plastic deformation behavior is correlated with the building principle of the crystal structures.

\section{Crystal Structures}

\subsection{Geometrical Principles in Frank-Kasper Polyhe- dra}

Frank and Kasper ${ }^{39,40)}$ described the crystal structures of a number of complex close-packed phases in terms of sphere packing with the basic stacking units of 12-, 14-, 15- and 16-coordinated polyhedra. Although the locally densest packing is achieved by tetrahedral packing, the space cannot be filled only with regular tetrahedral packing. Then, the regular tetrahedra are distorted to achieve the possibly densest local packing, leading to the formation of many different coordinated polyhedral described above, as observed in many of the $\mathrm{Fe}-\mathrm{Zn}$ intermetallics. Which of polyhedra is formed depends on the atomic radius ratios of the constituent elements.

If an icosioctahedron (16-coordinated polyhedron) is formed with two different constituent atoms (one at the center and the other at the vertex positions), the larger atom should reside at the center and the densest packing is achieved when the larger atom at the center has the atomic radius ratio of 1.345 (Fig. 2(a)). For the Fe- $\mathrm{Zn}$ binary system, this will be achieved with the $\mathrm{Zn}$ atom residing at the center, when referring to the Goldschmidt radii of $\mathrm{Fe}$ $(0.124 \mathrm{~nm})$ and $\mathrm{Zn}(0.133 \mathrm{~nm})$. On the other hand, if an icosahedron (12-coordinated polyhedron) is formed with two different constituent atoms in a similar way, the smaller atom should reside at the center and the densest packing is achieved when the smaller atom at the center has the atomic radius ratio of 0.902 (Fig. 2(b)). For the Fe-Zn binary system, this will be achieved with the Fe atom residing at the center of the icosahedron. Yet, this is not the case for the crystal structure of the $\delta_{\mathrm{lp}}$ phase determined previously by Belin et al. ${ }^{33)}$ In their crystal structure model, the center of icosahedra is always the larger $\mathrm{Zn}$ atom, and $\mathrm{Fe}$ atoms are allocated to the vertex positions in the so-called disordered icosahedron. ${ }^{33)}$ This is not consistent with the geometrical principles of the Frank-Kasper polyhedra.

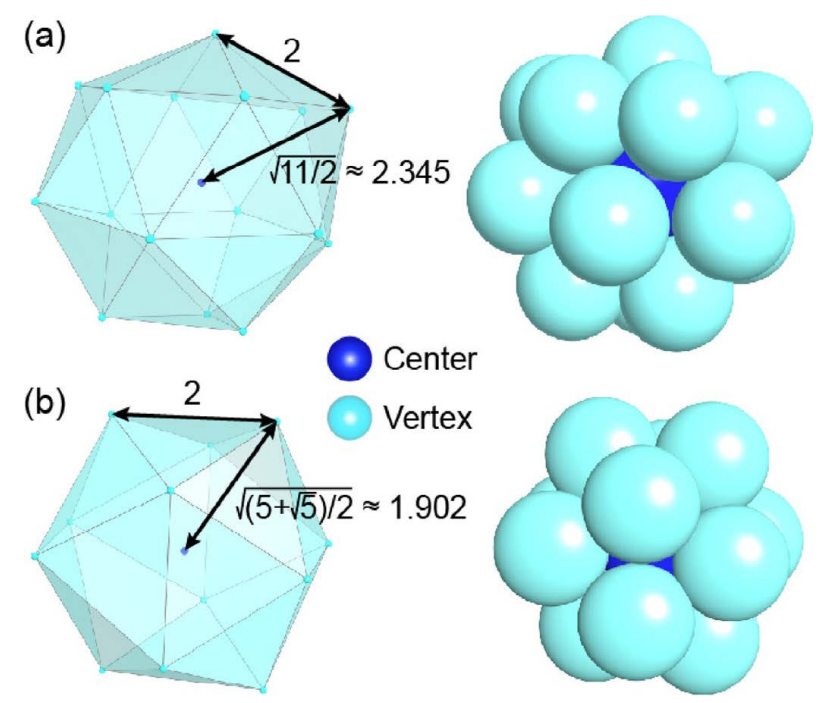

Fig. 2. Geometries of locally dense packed (a) icosioctahedron and (b) icosahedron. (Online version in color.) 


\subsection{Crystal Structures of the Five Phases in the Fe-Zn Binary System}

A solution growth method was employed to grow large crystal grains $(>300 \mu \mathrm{m})$ of the $\Gamma, \delta_{\mathrm{lk}}, \delta_{\mathrm{lp}}$ and $\zeta$ phase while a solid-state reaction of $\mathrm{Zn}$ and $\mathrm{Fe}$ powder was employed for the $\Gamma_{1}$ phase. ${ }^{4,11)}$ Experimental details of the crystal growth are described elsewhere. ${ }^{8,9,19,37)}$

\subsection{1. $\zeta$ Phase $\left(\mathrm{FeZn}_{13}\right)$}

The crystal structure of the $\zeta$ phase was first refined by Brown $^{27)}$ and then by Gellings et al. ${ }^{31)}$ both of who assigned a base-centered monoclinic unit cell, failing to determine the $\mathrm{Fe}$ atomic positions in the unit cell. Belin et $a l^{34)}$ subsequently refined the Fe positions to be exclusively at the center of the $\mathrm{Zn}_{12}$ icosahedron, although their lattice setting does not conform with the international convention that the oblique angle $\beta$ should be non-acute but be as close as $90^{\circ}{ }^{41)} \mathrm{Fe}$-centered $\mathrm{Zn}_{12}$ icosahedra are the structural unit and they are linked to one another by vertex-sharing to form a chain of $\mathrm{Zn}_{12}$ icosahedra along the $c$-axis, and isolated $\mathrm{Zn}$ atoms are located between the chains as if they act as glue among the chains in the $C$-centered monoclinic lattice (with the space group of $C 2 / m$ ), giving rise to the chemical formula of $\mathrm{FeZn}_{13}$ (Fig. 3) ${ }^{19,34)}$ If we take the origin of the monoclinic lattice shifted by half the $c$ axis, the crystal structure of the $\zeta$ phase can be described as being made up of $\mathrm{Zn}_{12}$ icosahedron with their central Fe atoms being located at the $C$-centered monoclinic lattice points together with the $\mathrm{Zn}$ atoms that act as glue among the icosahedra.

Some of isolated $\mathrm{Zn}$ atoms located between the chains of Fe-centered $\mathrm{Zn}_{12}$ icosahedra may be substituted with $\mathrm{Fe}$ atoms so that some solid-solubility range occurs in the Ferich side of the stoichiometric composition $\left(\mathrm{FeZn}_{13}: \mathrm{Zn}-7.1\right.$ at.\%Fe). Yet, the solid-solubility range of the $\zeta$ phase is reported to extend in the $\mathrm{Zn}$-rich side of the stoichiometry. ${ }^{4}$ This is not easily understood, since the extension of the solid-solubility range in the $\mathrm{Zn}$-rich side indicates that some $\mathrm{Fe}$ atoms allocated to the center of the $\mathrm{Zn}_{12}$ icosahedron are substituted by $\mathrm{Zn}$ atoms, which is not consistent with the geometrical principles in Frank-Kasper polyhedra (icosahedra). Indeed, the solid-solubility range of the $\zeta$ phase has recently been revised to extend in the Fe-rich side of the stoichiometry as shown in Fig. $1 .{ }^{11)}$ The $\zeta$ phase in the coating layer usually exhibits columnar grains elongated along the [001] directions, while no orientation relationship is found with the underlying $\delta_{\mathrm{lk}}$ phase. ${ }^{19)}$

\subsection{2. $\delta_{1 \mathrm{p}}$ Phase $\left(\mathrm{Fe}_{13} \mathrm{Zn}_{126}\right)$}

Belin et al ${ }^{33)}$ refined the crystal structure of the $\delta_{\text {lp }}$ phase by X-ray diffraction and reported that the huge hexagonal unit cell contains 556 atoms, of which 52 are $\mathrm{Fe}$ atoms although the chemical formula of the $\delta_{1 \mathrm{p}}$ phase of their model is designated as $\mathrm{FeZn}_{10}$ (Fig. 4(a)). The characteristic features of their model are that in addition to icosahedra, icosioctahedra and pentagonal prisms are included as coordinated polyhedra and that in the so-called disordered icosahedron, while a $\mathrm{Zn}$ atom is allocated to the center, $\mathrm{Fe}$ atoms are allocated to the vertex positions. The latter is not consistent with the geometrical principles of the FrankKasper polyhedra. Indeed, our results of direct observations of atoms in the $\delta_{\mathrm{lp}}$ phase are not consistent with Belin's
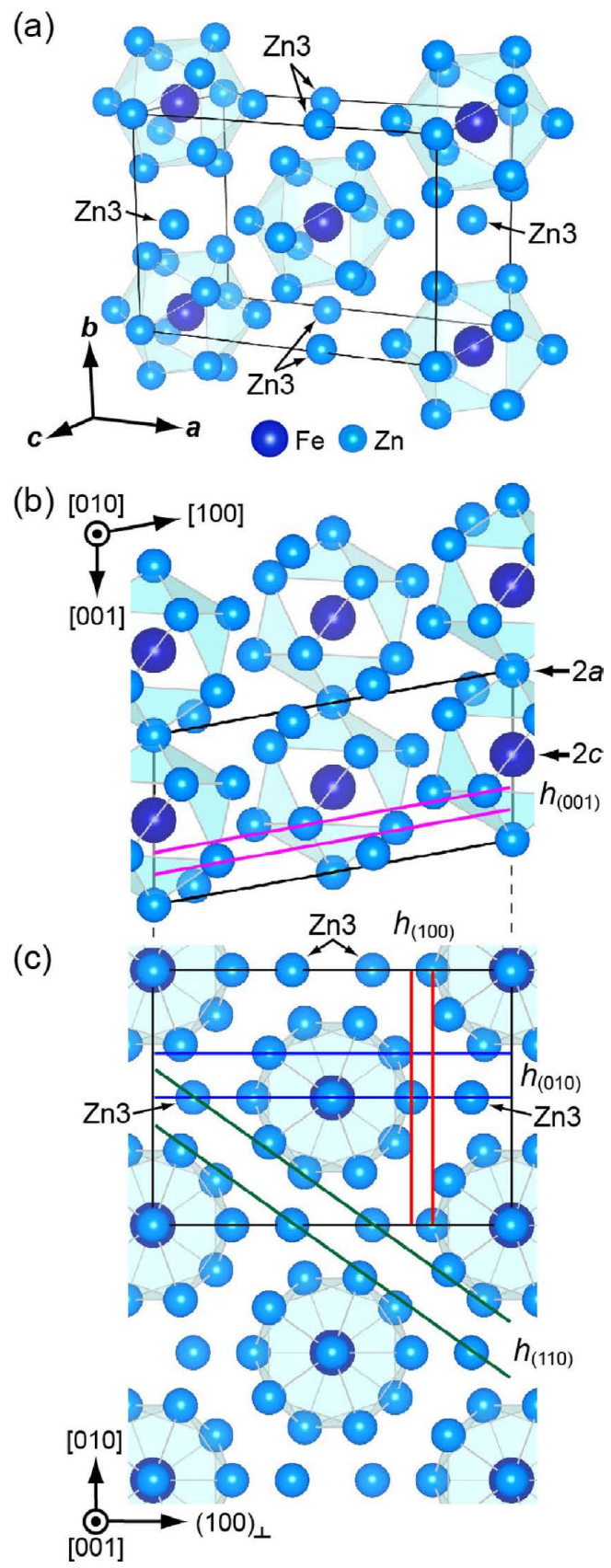

Fig. 3. (a) The crystal structure of the $\zeta$ phase. The Fe-centered $\mathrm{Zn}_{12}$ icosahedra are shown in light blue. (b) [010] and (c) [001] projections of the unit cells. ${ }^{19)}$ The four widest interplanar distances are shown in (b) and (c). (Online version in color.)

model, as shown in Fig. 4(b). When the STEM images are calculated based on the atomic coordinates given by Belin et al. ${ }^{33)}$ some bright spots corresponding to atoms in the experimental images are found to be missed in the calculated images and vice versa (Fig. 5). Then, crystal structure refinement can be done combining with STEM observations through comparing experimental and calculated images until the best matching is obtained. Our combined analysis of the $\delta_{1 \mathrm{p}}$ phase indicates that $\mathrm{Fe}$ atoms at vertices of disordered icosahedron in Belin's model are transferred to the center of the icosahedron and that $\mathrm{Zn}$ atoms at vertices of pentagonal prisms and icosahedron are transferred to vertices of the Fe-centered icosahedron. The net result is that (1) no pentagonal prism is included, (2) Fe atoms are never allo- 
(a) Belin et al. [Ref. 33]

(b) Okamoto et al. [Ref. 9]

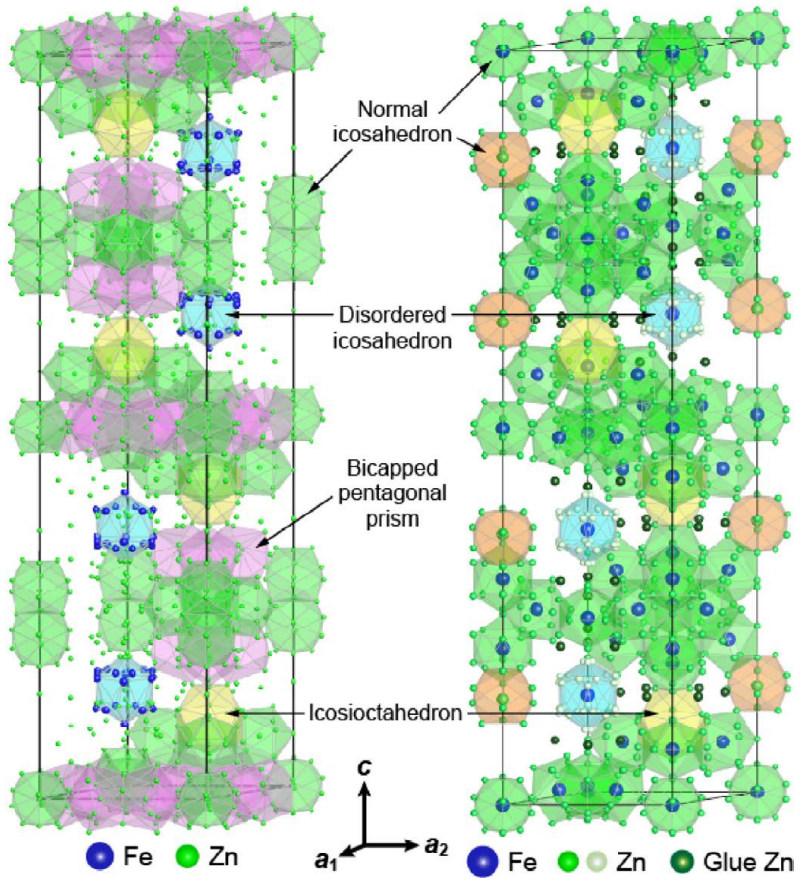

Fig. 4. The crystal structure model of the $\delta_{\mathrm{lp}}$ phase by (a) Belin et $a l^{33)}$ and (b) Okamoto et al. ${ }^{9)}$ (Online version in color.)

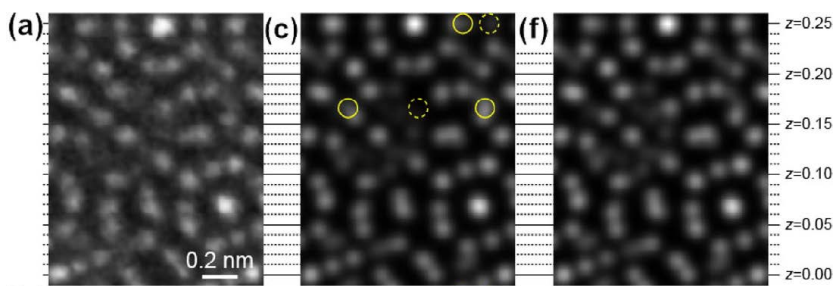

(b)

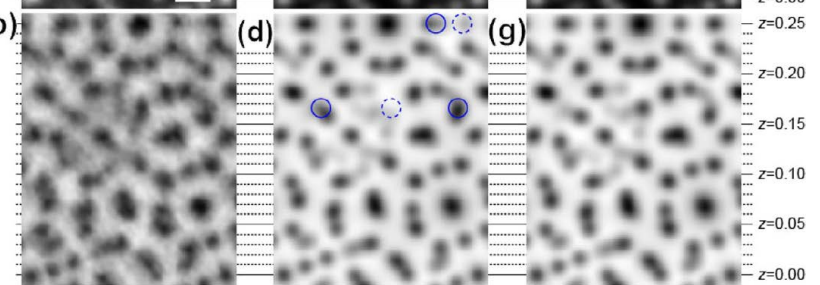

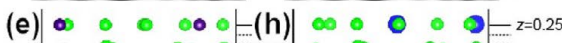

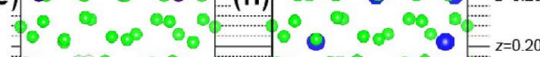

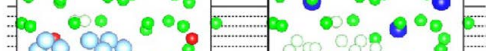

- Fe atoms

Fe atoms (disorder)

- $\mathrm{Zn}$ atoms

$\mathrm{Zn}$ atoms (disorder)

- $\mathrm{Zn}(7)$

- $\mathrm{Zn}(36)$

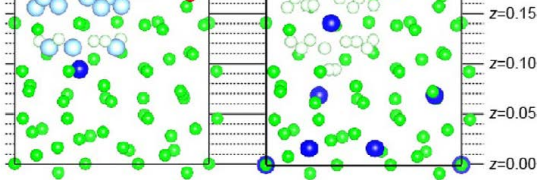

Fig. 5. (a) HAADF and (b) ABF images of a quarter unitcell of the $\delta_{\mathrm{lp}}$ phase simultaneously taken along the $[1 \overline{1} 00]$ zone axis with the spherical-aberration-corrected STEM. (c) HAADF and (d) ABF images calculated with the structural parameters reported by Belin $e$ al $^{33)}$ (f) HAADF and (g) ABF images calculated with the structural parameters refined in our study ${ }^{9}{ }^{9}$ The corresponding portion of [1 100$]$ projection of the structural models (e) reported by Belin et $a l^{33)}$ and (h) refined in our study.9) (Online version in color.)

cated at vertices of icosahedra, but (3) these Fe atoms are allocate at the center of $\mathrm{Zn}_{12}$ icosahedra. The structural unit is therefore the Fe-centered $Z_{12}$ icosahedron, as in the case of the $\zeta$ phase. In both the $\zeta$ and $\delta_{\mathrm{lp}}$ phases, the vertex sites

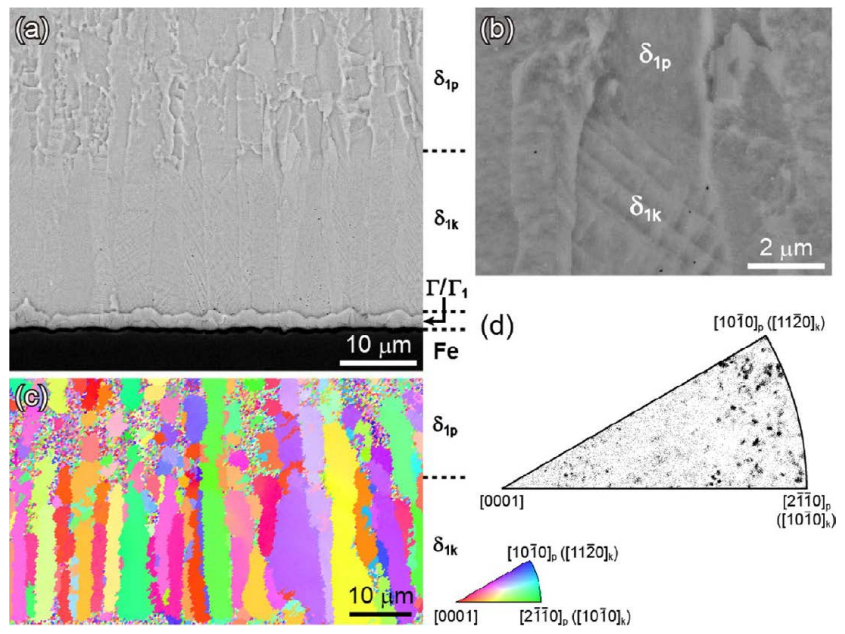

Fig. 6. (a) SEM backscattered electron image, (b) magnified image of interface, and (c) EBSD orientation mapping of a cross section of coating $\left(\delta_{\mathrm{lp}} / \delta_{\mathrm{lk}}\right)$ of post heat-treated GA steel. (d) Pole Fig. of growth direction of the $\delta_{\mathrm{lp}}$ and $\delta_{\mathrm{lk}}$ phases. (Online version in color.)

of Fe-centered icosahedra are occupied exclusively by $\mathrm{Zn}$ atoms, forming a pure $\mathrm{Zn}_{12}$ icosahedron so as to encapsulate an $\mathrm{Fe}$ atom at the center. ${ }^{9,19,34)}$ The large hexagonal unit cell of the $\delta_{1 \mathrm{p}}$ phase with the space group of $P 6_{3} / m m c$ comprises more or less regular (normal) $\mathrm{Zn}_{12}$ icosahedra, disordered $\mathrm{Zn}_{12}$ icosahedra, $\mathrm{Zn}_{16}$ icosioctahedra, and isolated $\mathrm{Zn}$ atoms. ${ }^{9)}$ The unit cell contains $52 \mathrm{Fe}$ and $504 \mathrm{Zn}$ atoms so that the compound is expressed with the chemical formula of $\mathrm{Fe}_{13} \mathrm{Zn}_{126}$, instead of $\mathrm{FeZn} \mathrm{n}_{10}$. ${ }^{\text {) }}$ Normal icosahedra are linked to one another by face- and vertex-sharing forming two types of basal slabs, which are bridged with each other by face-sharing with icosioctahedra, whereas disordered icosahedra with positional disorder at their vertex sites are isolated from other polyhedra. ${ }^{9,35)}$

\subsection{3. $\delta_{1 \mathrm{k}}$ Phase}

The crystal structure of the $\delta_{1 \mathrm{k}}$ phase has yet to be refined until now, although the phase is known to locate in the Fe-rich side next to the $\delta_{1 \mathrm{p}}$ phase, so that the compound is expressed with the chemical formula of $\mathrm{FeZn}_{7 .}{ }^{42)}$ Hong and Saka ${ }^{16)}$ reported that the $\delta_{1 \mathrm{k}}$ phase has a superlattice structure based on the $\delta_{\text {lp }}$ phase having a tripled periodicity along the $a$-axis direction of the $\delta_{1 \mathrm{p}}$ phase from the inspection of electron diffraction patterns. The tripled periodicity along the $a$-axis direction is believed to be due to higher-order chemical ordering of $\mathrm{Fe}$ atoms in excess of the solubility limit of the Fe content in the $\delta_{\mathrm{lp}}$ phase, although the atomic coordinates have never been clarified. Because of this, the stoichiometric composition of this compound, which is sometimes described to be $\mathrm{FeZn}_{7}$, is still an open question. However, the higher-order chemical ordering of $\mathrm{Fe}$ atoms in the parent $\delta_{\text {lp }}$ phase seems reasonable when judged from the formation sequence of the two phases as well as the existence of the orientation relationship between the two phases keeping their mutual $a$ - and $c$-axis directions parallel to each other (Fig. 6). We believe that the structural unit of this compound is still Fe-centered $\mathrm{Zn}_{12}$ icosahedron linked to one another by face- and vertex-sharing. There still exist some argument about the order (either the first- or secondorder) of phase transformation between the two phases, ${ }^{7,43)}$ 
although recently the first-order transformation is claimed to occur at least in the temperature range $450-500^{\circ} \mathrm{C} .{ }^{11)}$

Because of the tripled periodicity along the $a$-axis direction, three different equivalent stacking positions are generated in stacking an atomic slab with the thickness corresponding to the $c$-axis dimension of the parent $\delta_{1 \mathrm{p}}$ phase (Fig. 7). Then, multiplicity is generated for the stacking sequence of these atomic slabs along the $c$-axis direction. ${ }^{8)}$ The crystal structure can then be described in terms of the order-disorder (OD) theory ${ }^{8,44,45)}$ with these atomic slabs being called 'OD layer'. Depending on the stacking order, the crystal structure of the $\delta_{1 \mathrm{k}}$ phase can be ordered with various periodicities along the stacking direction (along the $c$-axis) or completely disordered. Based on the OD

(a) $a$

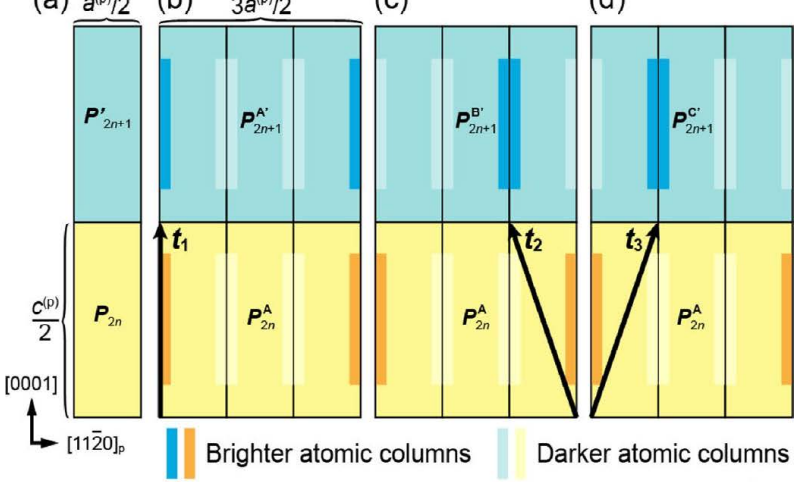

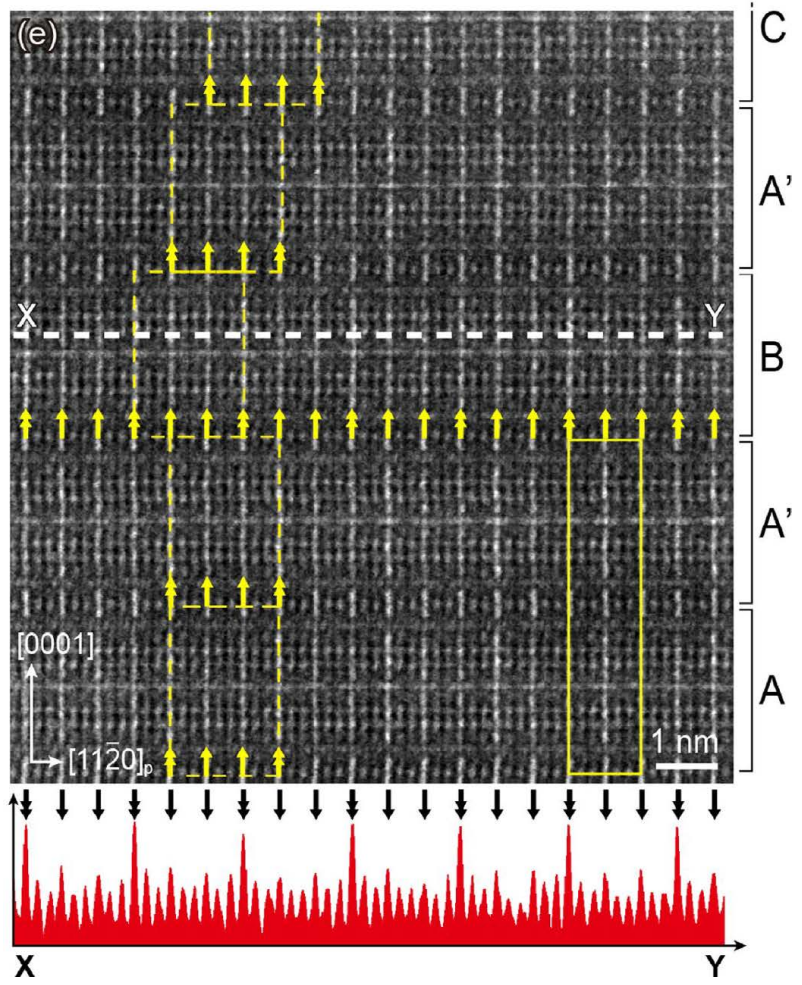

Fig. 7. Schematic illustrations of stacking manners of the structural blocks with the thickness of $c^{(\mathrm{p})} / 2$ in the (a) $\delta_{\mathrm{lp}}$ and (b-d) $\delta_{\mathrm{lk}}$ phases, respectively. ${ }^{8)}$ There are three different stacking manners in the $\delta_{\text {lk }}$ phase. (e) HAADF-STEM

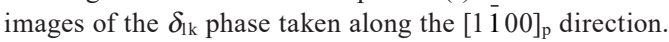
The solid frame indicates the unit cell of the $\delta_{\mathrm{lp}}$ phase. Single and double arrows in (b) indicate slightly darker and brighter atomic columns. The intensity profile along the dashed line $\mathrm{X}-\mathrm{Y}$ is shown in the bottom of (e). (Online version in color.) theory, ${ }^{8,44,45)}$ two maximum degree of order (MDO) polytypes belonging to the space groups of $\mathrm{P}_{3} / \mathrm{mcm}$ (MDO1) and $R 3 c(\mathrm{MDO} 2)$ are deduced for the $\delta_{1 \mathrm{k}}$ phase. The most stable MDO polytype in the OD family of the $\delta_{1 \mathrm{k}}$ phase is determined experimentally to be the MDO2 polytype. ${ }^{8)}$ However, the $\delta_{1 \mathrm{k}}$ phase may have a high chance to exhibit one-dimensional stacking disorder along the $c$-axis direction if the annealing condition is far from the equilibrium, as in the practice of GA steel production.

\subsection{4. $\quad \Gamma_{1}$ Phase $\left(\mathrm{Fe}_{21.2} \mathrm{Zn}_{80.8}\right)$}

The $\Gamma_{1}$ phase in the $\mathrm{Fe}-\mathrm{Zn}$ binary system is reported to crystallize into one of the so-called $\gamma^{\prime}$-brass structures (space group $F \overline{4} 3 m$ ), ${ }^{32)}$ whose crystal structures are usually described as a $2 \times 2 \times 2$ superstructure based on the $\gamma$-brass structure with a doubled lattice constant of the cubic unit cell so that the unit cell volume for the $\gamma$ '-brass structure is eight times that for the $\gamma$-brass structure, into which the $\Gamma$ phase compound crystallizes. ${ }^{46-49)}$ Koster and Schoone, ${ }^{32)}$ made a first refinement of crystal structure of the intermetallics of the $\Gamma_{1}$ phase in the $\mathrm{Fe}-\mathrm{Zn}$ system. According to the atomic coordinates reported by Koster and Schoone, ${ }^{32)}$ the crystal structure of the $\Gamma_{1}$-phase compound whose chemical composition is determined to be $\mathrm{Fe}_{11} \mathrm{Zn}_{40}$ can be considered to consist of $(\mathrm{Zn}, \mathrm{Fe})_{12}$ icosahedra as in the case of other compounds in the $\mathrm{Fe}-\mathrm{Zn}$ system. Some Fe atoms start to occupy the vertex sites of icosahedra to form $(\mathrm{Zn}, \mathrm{Fe})_{12}$ icosahedra because of the increased Fe content in the compound. However, the central site of some of the constituting icosahedra are occupied not only by Fe but also by $\mathrm{Zn}$ atoms. This is somewhat questionable when referring to the geometrical principles in Frank-Kasper polyhedra. Indeed, our results by synchrotron X-ray diffraction have indicated that the $\Gamma_{1}$-phase compound consists of $\mathrm{Zn}_{12}$ and $(\mathrm{Zn}, \mathrm{Fe})_{12}$ icosahedra whose central site is exclusively occupied by Fe atoms (Fig. 8) ${ }^{37)}$ That is, while an Fe atom exclusively occupy the center of icosahedra, vertices of some icosahedra are occupied exclusively by $\mathrm{Zn}$ atoms but those of others are occupied not only by $\mathrm{Zn}$ but also by Fe atoms. This leads to the formation of both Fe-centered $Z_{n_{12}}$ and Fe-centered $(\mathrm{Zn}, \mathrm{Fe})_{12}$ icosahedra as the structural units (Fig. 8). They are connected to one another by vertex- and face-sharing, respectively, with isolated $\mathrm{Zn}$ atoms forming a $\mathrm{Zn}_{4}$ tetrahedron between the agglomerated polyhedra. ${ }^{37)}$ The unit cell contains 408 atoms (Pearson symbol $c F 408$ ), of which 84.8 are $\mathrm{Fe}$ atoms, and $323.2 \mathrm{Zn}$ atoms. The $\Gamma_{1}$ phase is formulated thus to be $\mathrm{Fe}_{21.2} \mathrm{Zn}_{80.8}$ instead of $\mathrm{Fe}_{11} \mathrm{Zn}_{40}$ as previously described by Koster and Schoone. ${ }^{32)}$ The chemical composition corresponding to the formula of $\mathrm{Fe}_{21.2} \mathrm{Zn}_{80.8}$ is very close to the peritectic composition of the $\Gamma_{1}$ phase in the recently revised phase diagram (Fig. 1). ${ }^{11)}$

\subsection{5. $\Gamma$ Phase $\left(\mathrm{Fe}_{4} \mathrm{Zn}_{9}\right)$}

The intermetallic of the $\Gamma$ phase, the most Fe-rich compound in the $\mathrm{Fe}-\mathrm{Zn}$ system, is known to crystallize into the so-called $\gamma$-brass structure ${ }^{26,28,29,48)}$ that comprises $(\mathrm{Zn}, \mathrm{Fe})_{12}$ icosahedra (Fig. 9). Vertices of all icosahedra are occupied not only by $\mathrm{Zn}$ but also by Fe atoms, because of the Fe-richest composition. The structural unit of the $\Gamma$ phase is thus the $\mathrm{Fe}$-centered $(\mathrm{Zn}, \mathrm{Fe})_{12}$ icosahedron. However, there are some discrepancies in the results of crystal structure refine- 
(a) Fe4@(Fe,Zn) $)_{12}$

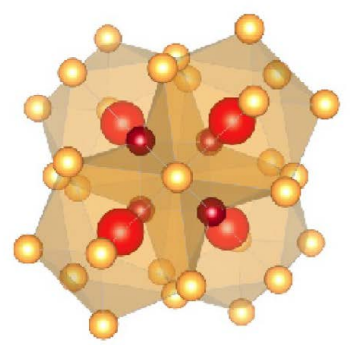

(c) Fe1@(Fe,Zn) 12

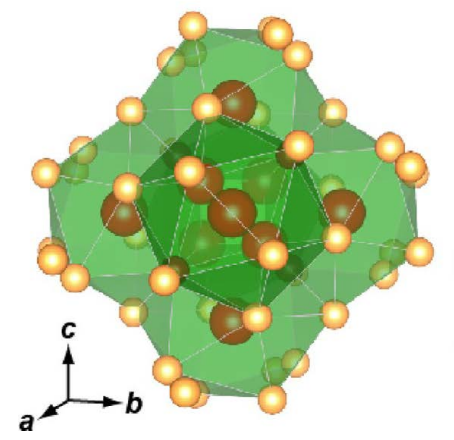

(b) Fe2@Zn $\mathrm{Zn}_{12}$

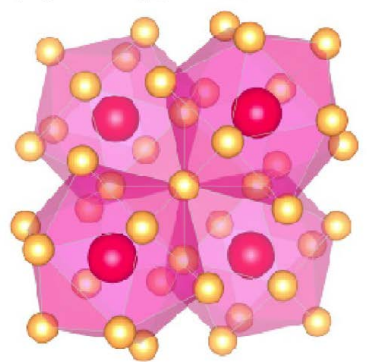

(d) $\mathrm{Zn}_{4}$ tetrahedron

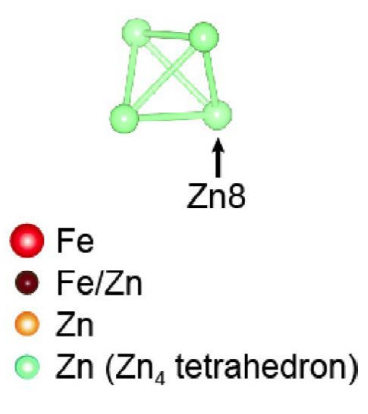

Fig. 8. Agglomerated polyhedra constituting the crystal structure of the $\Gamma_{1}$ phase. $^{37)}$ (a) Four Fe4-centered $(\mathrm{Fe}, \mathrm{Zn})_{12}$ icosahedra connected with one another by face-sharing. (b) Four Fe2-centered $\mathrm{Zn}_{12}$ icosahedra connected with one another by vertex-sharing. (c) Four Fel-centered (Fe,Zn) $)_{12}$ icosahedra connected with one another by face-sharing. (d) $\mathrm{Zn}_{4}$ tetrahedron filling the remained space which is not occupied by the agglomerated polyhedra. (Online version in color.)

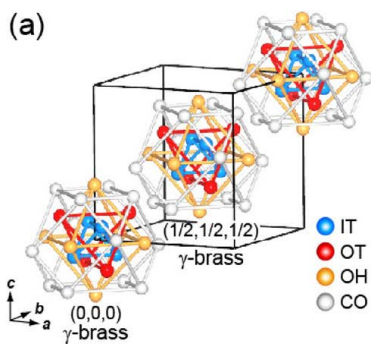

(b)

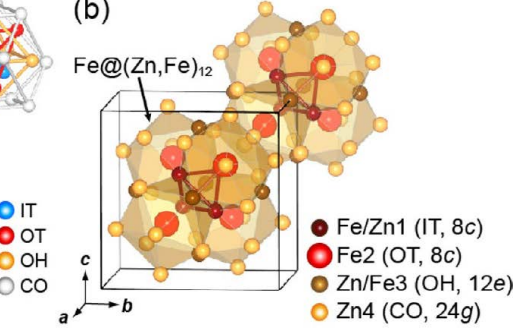

Fig. 9. Unit cell of the $\Gamma$ phase ${ }^{37)}$ described in (a) the nested cluster model ${ }^{46,48)}$ and (b) the coordination polyhedra model. (a) Unit cell of the $\gamma$-brass structure consisting of two $\gamma$-brass type (26 atoms) clusters residing at the cell corner and body centre. ${ }^{26)}$ (b) Unit cell of the $\Gamma$ phase consists of the agglomerated $\mathrm{Fe}$-centred $(\mathrm{Zn}, \mathrm{Fe})_{12}$ icosahedra. (Online version in color.)

ment made in the past by four research groups in the Fe and $\mathrm{Zn}$ occupancy behaviors especially for the central site of these $(\mathrm{Zn}, \mathrm{Fe})_{12}$ icosahedra. While exclusive occupancy by $\mathrm{Zn}$ atoms was claimed by Johansson et al., ${ }^{28)}$ exclusive occupancy by $\mathrm{Fe}$ atoms was claimed by Brandon et al., ${ }^{29)}$ Belin et al., ${ }^{33)}$ and Xie et al. ${ }^{50)}$ Our results of crystal structure refinement of the $\Gamma$ phase compounds with some different chemical compositions by synchrotron X-ray diffraction have indicated that the central site of $(\mathrm{Zn}, \mathrm{Fe})_{12}$ icosahedra is occupied exclusively by an $\mathrm{Fe}$ atom regardless of chemical compositions (Fig. 9). The $\Gamma$ phase compound consists of Fe-centered $(\mathrm{Zn}, \mathrm{Fe})_{12}$ icosahedra that connect with one another by face-sharing. The icosahedral vertex sites of
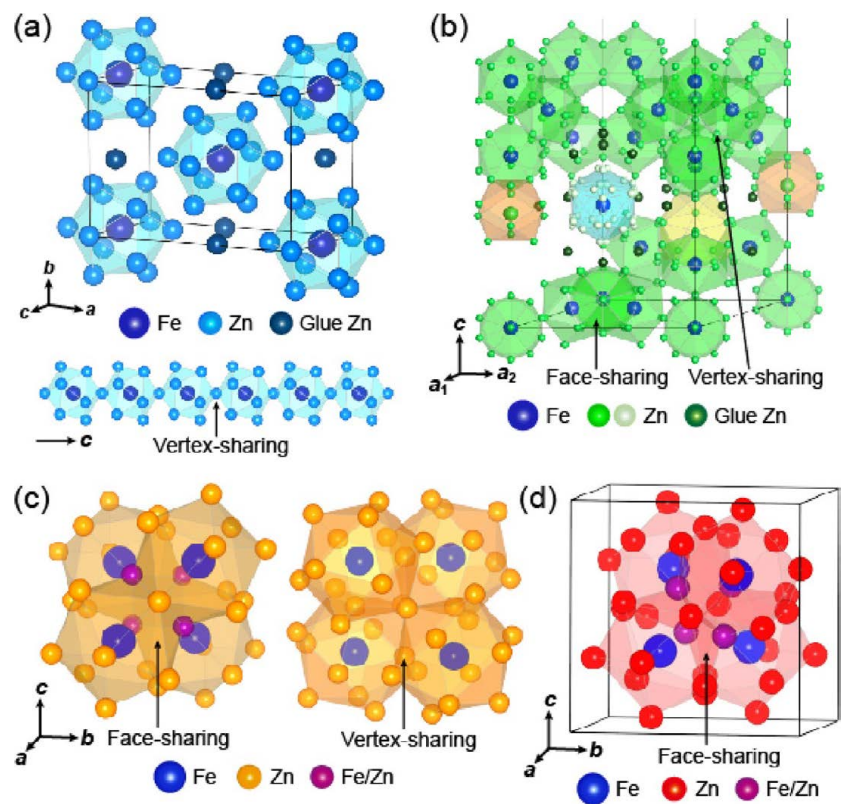

Fig. 10. Crystal structures and connecting behaviour of the coordination polyhedra (Fe-centered $(\mathrm{Fe}, \mathrm{Zn})_{12}$ icosahedra) in the Fe-Zn intermetallic compounds, (a) $\zeta$, (b) $\delta_{\mathrm{lp}}$, (c) $\Gamma_{1}$ and (d) $\Gamma^{37)}$ (Online version in color.)

the shared triangle faces are occupied by Fe and $\mathrm{Zn}$ atoms to form a $(\mathrm{Fe}, \mathrm{Zn})_{4}$ tetrahedral core and the Fe occupancy increases with the increase in the $\mathrm{Fe}$ content of the compounds (Fig. 9). The stoichiometry of the $\Gamma$ phase occurs at the peritectic composition and is expressed as $\mathrm{Fe}_{4} \mathrm{Zn}_{9}(\mathrm{Zn}-$ 30.77 at. $\% \mathrm{Fe}$ ), where the center of the icosahedra and the vertices of the shared triangle faces are all occupied exclusively by Fe atoms while the other vertex sites by $\mathrm{Zn}$ atoms. The chemical composition corresponding to the formula of $\mathrm{Fe}_{4} \mathrm{Zn}_{9}$ is indeed very close to the peritectic composition of the $\Gamma$ phase in the recently revised phase diagram (Fig. 1). ${ }^{11)}$

Some reports described the cube-on-cube orientation relationships among the three phases $\left(\alpha, \Gamma\right.$ and $\left.\Gamma_{1}\right) .^{51,52)}$ This is consistent with the expectation from the fact that the crystal structure of the $\Gamma$-phase compound is sometimes described as a $3 \times 3 \times 3$ superlattice structure based on the BCC (body-centered cubic) structure with the tripled lattice constant ${ }^{26)}$ and that of the $\Gamma_{1}$-phase compound is regarded as a $2 \times 2 \times 2$ superlattice structure based on the structure of the $\Gamma$-phase compound. ${ }^{49,53)}$ On the other hand, there are other reports to show no orientation relationships among the three phases. ${ }^{54-56)}$ Our study indicates that generally, there is no orientation relationship both between the $\Gamma$ and $\Gamma_{1}$ phases and between the $\alpha(\mathrm{BCC}-\mathrm{Fe})$ and $\Gamma$ phases in the coating layer of GA steel sheet. ${ }^{37)}$

\subsection{Building Principle of the Crystal Structures}

In the $\zeta$ phase, the most Fe-lean compound in the $\mathrm{Fe}-\mathrm{Zn}$ system (Fig. 10(d)), Fe-centered $\mathrm{Zn}_{12}$ icosahedra are linked to one another by vertex-sharing to form a chain of $\mathrm{Zn}_{12}$ icosahedra along the $c$-axis, ${ }^{34)}$ and isolated $\mathrm{Zn}$ atoms are located between the chains ${ }^{19)}$ (Fig. 10(d)). In the $\delta_{\text {lp }}$ phase, located next to the $\zeta$ phase in the Fe-rich side in the $\mathrm{Fe}-\mathrm{Zn}$ binary phase diagram (Fig. 10(c)), the structural unit is again the Fe-centered $\mathrm{Zn}_{12}$ icosahedron and these Fe-centered $\mathrm{Zn}_{12}$ icosahedra are connected to one another by vertex- and 
face-sharing with isolated $\mathrm{Zn}$ atoms between vertex- and face-shared Fe-centered $Z_{12}$ icosahedron (Fig. 10(c)). ${ }^{9,35)}$ In both the $\zeta$ and $\delta_{1 \mathrm{p}}$ phases, the vertex sites of Fe-centered icosahedra are occupied exclusively by $\mathrm{Zn}$ atoms, forming pure $\mathrm{Zn}_{12}$ icosahedron so as to encapsulate an $\mathrm{Fe}$ atom at the center. ${ }^{9,34,35)}$ In the $\Gamma_{1}$ phase, located next to the $\delta_{\mathrm{lp}} / \delta_{1 \mathrm{k}}$ phases in the Fe-rich side in the $\mathrm{Fe}-\mathrm{Zn}$ binary phase diagram, while the center of icosahedra is exclusively occupied by an Fe atom, vertices of some icosahedra are occupied exclusively by $\mathrm{Zn}$ atoms but those of other icosahedra are occupied not only by $\mathrm{Zn}$ but also by $\mathrm{Fe}$ atoms. This occurs because Fe atoms that cannot be allocated to the center of icosahedra occupy some vertex sites. This leads to both Fe-centered $\mathrm{Zn}_{12}$ and $\mathrm{Fe}$-centered $(\mathrm{Zn}, \mathrm{Fe})_{12}$ icosahedra as the structural units (Fig. 10(b)). They are connected to one another by vertex- and face-sharing, respectively, with isolated $\mathrm{Zn}$ atoms forming a $\mathrm{Zn}_{4}$ tetrahedron between the agglomerated polyhedra (Fig. $8(\mathrm{~d})$ ). In the $\Gamma$ phase, the most Fe-rich compound in the Fe- $\mathrm{Zn}$ system, while the center of icosahedra is exclusively occupied by an Fe atom, vertices of these icosahedra are occupied by both $\mathrm{Zn}$ and $\mathrm{Fe}$ atoms. The structural unit of the $\Gamma$ phase is thus the Fecentred $(\mathrm{Zn}, \mathrm{Fe})_{12}$ icosahedron and they are connected with one another in a tetrahedrally close-packed arrangement by face-sharing (Fig. 10(a)).

The variation of the crystal structures of all these Fe- $\mathrm{Zn}$ compounds with chemical composition can be best understood by considering the packing of coordinated polyhedra with the common structural unit being the $\mathrm{Zn}_{12}$ and/ or $(\mathrm{Zn}, \mathrm{Fe})_{12}$ icosahedron whose central site is exclusively occupied by an $\mathrm{Fe}$ atom (Fig. 10). Exclusive occupancy of an Fe atom at the center of the $\mathrm{Zn}_{12}$ and/or $(\mathrm{Zn}, \mathrm{Fe})_{12}$ icosahedron is consistent with the geometrical principles in Frank-Kasper polyhedra, in which the smaller atom ( $\mathrm{Fe}$ in this case) is concluded to reside at the center of the icosahedron formed by the larger atoms ( $\mathrm{Zn}$ in this case) for the formation of icosahedron with two constituent elements with different atomic radii. When the Fe content is increased so that all $\mathrm{Fe}$ atoms cannot be accommodated in the central sites of these icosahedra, these excess Fe atoms occupy vertices of some icosahedra together with $\mathrm{Zn}$ atoms, forming $(\mathrm{Zn}, \mathrm{Fe})_{12}$ icosahedron. As a whole, the building principle of the crystal structures of the $\mathrm{Fe}-\mathrm{Zn}$ intermetallics is described as follows. As the Fe content of the Fe- $\mathrm{Zn}$ intermetallics increases, (i) the linkage geometry among Fe-centered icosahedra changes from vertex-sharing to facesharing, (ii) the atoms occupancy (either $\mathrm{Zn}$ or Fe atoms) at the face-sharing sites changes from exclusive occupancy by $\mathrm{Zn}$ atoms to mixed occupancy by $\mathrm{Zn}$ and Fe atoms and to exclusive occupancy by Fe atoms, and (iii) the fraction of isolated $\mathrm{Zn}$ atoms tends to decrease $(7.1 \%$ ( $\zeta) \rightarrow 9.4 \%$ $\left.\left(\delta_{\mathrm{lp}}\right) \rightarrow 3.9 \%\left(\Gamma_{1}\right) \rightarrow 0 \%(\Gamma)\right) .{ }^{37)}$

\section{Mechanical Properties}

\subsection{Prediction of Plasticity Based on the Peierls- Nabarro Model}

Plasticity (deformability) of materials is sometimes predicted based on the Peierls - Nabarro (PN) model, ${ }^{57,58)}$ in which the shear stress required to move an edge dislocation is expressed with the interplanar distance of slip plane $(h)$ and the magnitude of Burgers vector $(b)$, as described below.

$$
\tau_{p}=\frac{2 \mu}{1-v} \exp \left(-\frac{2 \pi h}{(1-v) b}\right)
$$

where $\mu$ and $v$ are the shear modulus and Poisson's ratio. According to Eq. (1), the slip system with a large value of the $h / b$ ratio is expected to operate more easily, since the value of $\tau_{\mathrm{p}}$ is expected to be smaller as the $h / b$ ratio increases. The low value of the $h / b$ ratio leads to the high Peierls-Nabarro stress to move dislocations, generally resulting in material brittleness. The $h / b$ ratios for all these $\mathrm{Fe}-\mathrm{Zn}$ intermetallic compounds $(0.058-0.183)$ are considerably smaller than that for iron (0.817) (Table 1), suggesting the brittleness for all these $\mathrm{Fe}-\mathrm{Zn}$ intermetallics. However, some (at least) of these intermetallics should exhibit some deformability, since GA steels can be bent, stretched and drawn under optimized forming conditions without serious coating failure.

\subsection{Micropillar Compression Testing}

Recent advances in fabrication processes with precise control of material dimensions down to the nanometer level, for example, with the focused ion beam (FIB) method have made it possible to investigate mechanical properties at these small scales using a nano-indenter with a flat punch. ${ }^{59-62)}$ This testing method is called micropillar compression testing and has used for a number of different materials. ${ }^{63-67)} \mathrm{We}$ investigate the compression deformation behavior of FIB-fabricated micropillar specimens cut from each of the five intermetallic phases in the GA coating at room temperature, in order to elucidate the mechanical properties for the respective phases. Our compression experiments of polycrystalline micropillars of each of the five phases prepared from the thin coating layer $(\sim 10 \mu \mathrm{m})$ of the GA steels have shown that the $\Gamma$ and $\zeta$ phases are deformable while $\Gamma_{1}, \delta_{1 \mathrm{k}}$ and $\delta_{\mathrm{lp}}$ phases are all considerably brittle. ${ }^{18,38)}$ This is somewhat consistent with Table 1 in that the $\Gamma$ and $\zeta$ phases have higher $h / b$ ratios than the others, although these $h / b$ ratios were calculated without taking account of detailed mechanisms such as dislocation dissociation (shorter Burgers vector length). With the knowledge of the deformability for the respective phases, crack initiation and propagation in the coating of GA steel upon forming can be discussed, as was done in our previous study. ${ }^{18)}$

We have extended the work on micropillar compression of polycrystals to single crystals to explore operative slip systems and their bulk critical resolved shear stress (CRSS) values. We have found during the course of single-crystal micropillar compression tests that the $\delta_{\mathrm{lp}}$ and $\delta_{\mathrm{lk}}$ phases are also deformable, as in the case of the $\Gamma$ and $\zeta$ phases. This may be reasonable in view of the fact that the optimum formability of GA steels is achieved when the coating layer consists mostly of the $\delta_{1}\left(\delta_{1 \mathrm{k}} / \delta_{1 \mathrm{p}}\right)$ phase. The details of the plastic deformation behavior of each of the five phases will be described in the following sections.

\subsection{Plastic Deformation Behavior of the Five Phases in the Fe-Zn Binary System}

\subsection{1. $\zeta$ Phase $^{19)}$}

Significant large strains (more than 10\%) are usually 
Table 1. Crystal structure parameters, Burgers vectors, and interplanar distances of slip planes for the Fe- $\mathrm{Zn}$ intermetallic compounds and pure iron. ${ }^{18)}$

\begin{tabular}{|c|c|c|c|c|c|c|c|c|}
\hline & Formula & $\begin{array}{l}\text { Pearson } \\
\text { symbol }\end{array}$ & Space group & $\begin{array}{l}\text { Lattice constant } \\
\qquad(\mathrm{nm})\end{array}$ & $\begin{array}{l}\text { Burgers } \\
\text { vector, } b\end{array}$ & $\begin{array}{l}\text { Interplanar } \\
\text { distance, } h\end{array}$ & $h / b$ & $\begin{array}{l}\text { Plastic deformation in } \\
\text { polycrystalline micropillars }\end{array}$ \\
\hline$\Gamma^{\mathrm{a}}$ & $\mathrm{Fe}_{4} \mathrm{Zn}_{9}$ & cI52 & $I \overline{4} 3 \mathrm{~m}$ & $a=0.8976$ & $\begin{array}{l}1 / 2<111>^{f} \\
0.777 \mathrm{~nm}\end{array}$ & $\begin{array}{c}\{110\}^{\mathrm{f}} \\
0.135 \mathrm{~nm}\end{array}$ & 0.174 & Yes \\
\hline$\Gamma_{1}^{\mathrm{a}}$ & $\mathrm{Fe}_{21.2} \mathrm{Zn}_{80.8}$ & $c F 408$ & $F \overline{4} 3 m$ & $a=1.7989$ & $\begin{array}{c}1 / 2<110>\mathrm{g} \\
1.272 \mathrm{~nm}\end{array}$ & $\begin{array}{c}\{111\}^{\mathrm{g}} \\
0.137 \mathrm{~nm}\end{array}$ & 0.108 & No \\
\hline$\delta_{1 \mathrm{k}}^{\mathrm{b}}$ & $\mathrm{FeZn}_{7}$ & - & $\begin{array}{l}\text { (higher-ordered } \\
\text { structure based } \\
\text { on } \delta_{\mathrm{lp}} \text { ) }\end{array}$ & $a=2.2148$ & $\begin{array}{l}1 / 3<1120>^{f} \\
2.222 \mathrm{~nm}\end{array}$ & $\begin{array}{c}(0001)^{\mathrm{f}} \\
0.1298 \mathrm{~nm}\end{array}$ & 0.058 & No \\
\hline$\delta_{\mathrm{lp}}^{\mathrm{c}}$ & $\mathrm{Fe}_{13} \mathrm{Zn}_{126}$ & $h P 556$ & $\mathrm{~Pb}_{3} / m m c$ & $\begin{array}{l}a=1.2830 \\
c=5.7286\end{array}$ & $\begin{array}{c}1 / 3<1120>^{f} \\
1.283 \mathrm{~nm}\end{array}$ & $\begin{array}{c}(0001)^{\mathrm{f}} \\
0.1298 \mathrm{~nm}\end{array}$ & 0.101 & No \\
\hline$\zeta^{\mathrm{d}}$ & $\mathrm{FeZn}_{13}$ & $m C 28$ & $C 2 / m$ & $\begin{array}{l}a=1.0862 \\
b=0.7608 \\
c=0.5061 \\
\beta=100.32^{\circ}\end{array}$ & $\begin{array}{c}1 / 2<112>\text { f,h } \\
0.770 \mathrm{~nm}\end{array}$ & $\begin{array}{c}\{110\}^{\mathrm{fhh}} \\
0.1412 \mathrm{~nm}\end{array}$ & 0.183 & Yes \\
\hline $\mathrm{Fe}^{\mathrm{e}}$ & - & $c I 2$ & $\operatorname{Im} \overline{3} m$ & $a=0.2867$ & $\begin{array}{l}1 / 2<111> \\
0.2483 \mathrm{~nm}\end{array}$ & $\begin{array}{c}\{110\} \\
0.2027 \mathrm{~nm}\end{array}$ & 0.817 & Yes \\
\hline
\end{tabular}

${ }^{\mathrm{a}}$ N. L. Okamoto et al. ${ }^{37)}$

${ }^{b}$ N. L. Okamoto et al. ${ }^{8)}$

${ }^{\mathrm{c}} \mathrm{N}$. L. Okamoto et al. ${ }^{9}$

${ }^{\mathrm{d}} \mathrm{R}$. Belin et al. ${ }^{34)}$

${ }^{\mathrm{e}} \mathrm{R}$. Kohlhaas et al. ${ }^{73)}$

${ }_{\text {f }}$ Slip systems were determined via compression tests of single-crystal micropillars.

${ }^{\mathrm{g}}$ The shortest Burgers vector and the plane with the largest interplanar distance were selected for the anticipated operative slip system.

${ }^{\mathrm{h}} \mathrm{N}$. L. Okamoto et al. ${ }^{19)}$

observed in micropillar compression at room temperature for single crystals of many different orientations (Fig. 11(a)). Deformation markings are easily observed on deformed micropillar specimens so that the slip plane is determined through trace analysis on two orthogonal surfaces (Figs. 1(b) and 1(c)). The slip direction is also easily determined if the possible slip direction is intended to lay on one of the side surfaces (Fig. 11(d)). The major slip system, $\{110\}<1 \overline{1} 2>$ is identified in that way to be operative in a very wide range of crystal orientation. In a narrow orientation range where $\{110\}<1 \overline{1} 2>$ slip cannot be operative, another slip system, (100)[001] is identified to operate. The CRSS value tends to increase with the decrease in the specimen size according to a power-law scaling. The bulk CRSS values deduced by extrapolating the inverse-power law size dependence of CRSS to the specimen size of 20-30 $\mu \mathrm{m}$ are $\sim 70 \mathrm{MPa}$ for $\{110\}<1 \overline{1} 2>$ slip and $\sim 240 \mathrm{MPa}$ for (100) [001] slip.

The slip systems observed to operate in the $\zeta$ phase are predicted respectively to be only the fourth and sixth easiest slip systems from the $h / b$ ratio, if (110), (010), (100) and (001) are considered as possible slip planes and [001], [1 $\overline{10}],[1 \overline{1} 2]$ and $[1 \overline{1} \overline{2}]$ as possible slip directions. Slip on $\{110\}[001],(010)[001]$ and $\{110\}<110>$ are predicted for the three easiest slip systems. The selection of slip planes and directions is believed to be closely related to the arrangement of Fe-centered $\mathrm{Zn}_{12}$ icosahedra in the $C$-centered monoclinic lattice. In view of the fact that the average bonding distance between $\mathrm{Fe}$ and $\mathrm{Zn}$ atoms in the icosahedron $(0.2590 \mathrm{~nm})$ is much shorter than that between $\mathrm{Zn}$ atoms at vertex sites of the icosahedron $(0.2782 \mathrm{~nm})$, the bonding between $\mathrm{Fe}$ and $\mathrm{Zn}$ atoms is so strong that slip deformation occurs so as not to destroy the Fe-centered $\mathrm{Zn}_{12}$ icosahedron. In other words, each individual Fe-centered
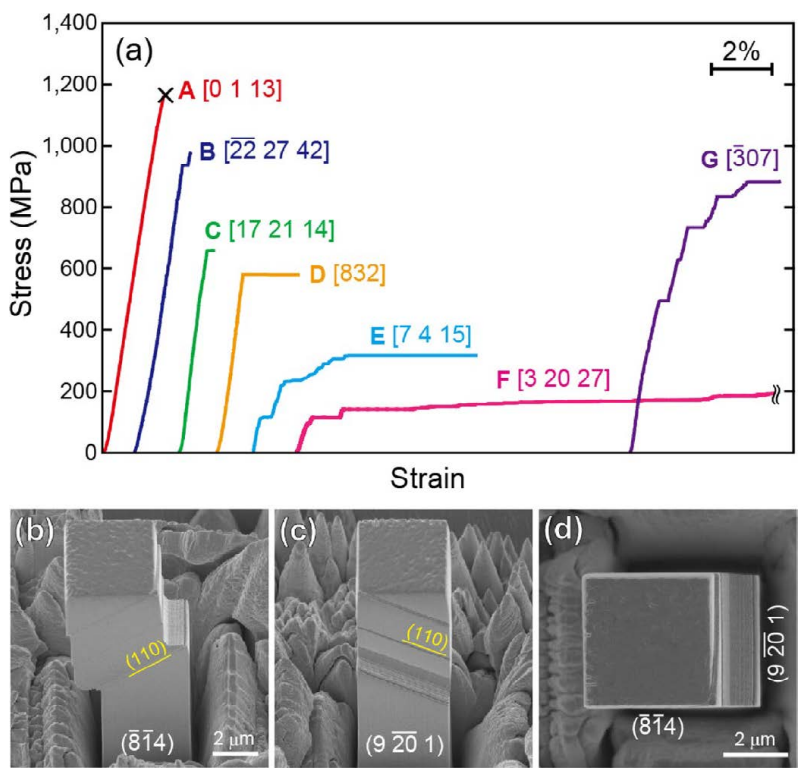

Fig. 11. Stress-strain curves obtained for seven micropillar specimens of the $\zeta$ phase compound with the orientations $\mathrm{A}-\mathrm{G} .{ }^{19)}$ The edge length is $\sim 4 \mu \mathrm{m}$ for all specimens. The mark $\times$ indicates the occurrence of failure. (b-d) SEM secondary electron images of deformation structures in the micropillar with the orientation E ([ $\left.\left.\begin{array}{lll}7 & 4 & 15\end{array}\right]\right)$. (a) and (b) were taken along a direction inclined by $30^{\circ}$ from the loading axis, while (c) was taken along the loading axis. (Online version in color.)

$\mathrm{Zn}_{12}$ icosahedron behaves as if it is a large-sized atom during slip deformation so that the slip plane is determined as one that does not break any atomic bonding within the Fe-centered $Z_{12}$ icosahedra during slip. This can be realized in the $\zeta$ phase compound, since in the crystal structure, Fe-centered $\mathrm{Zn}_{12}$ icosahedra (the structural unit) are linked 
to one another by vertex-sharing to form a chain of $\mathrm{Zn}_{12}$ icosahedra along the $c$-axis. This means that the slip plane to be selected should not destroy the vertex-shared $c$-axis chains of Fe-centered $Z_{12}$ icosahedra. The $\{110\}$ plane is such a plane with the widest interplanar distance and the (100) plane has the second widest (Fig. 3(c)), as reflected in the difference in the CRSS values for these two slip systems.

There are some other possible slip vectors on the (110) slip plane. Those include [001] and $1 / 2<110>$, both of which are actually shorter than $1 / 2<112>$. In view of the magnitude of the slip vector, the shorter is favorable. Nevertheless, $1 / 2<1 \overline{12}>$, which is not the shortest translation vector, is selected as the slip vector on the (110) slip plane. The selection of the slip vector is indeed closely associated with the dislocation dissociation, since the magnitude of the Burgers vector for dislocations with $\boldsymbol{b}=1 / 2<112>$ can be shortened as a result of dissociation. TEM observations (Fig. 12) have clearly indicates dislocation dissociation into three collinear superpartials, as described below.

$$
1 / 2[1 \overline{1} 2] \rightarrow 1 / 5[1 \overline{1} 2]+1 / 5[1 \overline{1} 2]+1 / 10[1 \overline{1} 2]
$$

This is further confirmed by calculation of the overlapping atomic volume along the slip direction on the slip plane.

\subsection{2. $\delta_{1 \mathrm{p}}$ Phase}

Since both the $a$ - and $c$-axis lengths $(1.283$ and $5.729 \mathrm{~nm}$, respectively) of the hexagonal unit cell of the $\delta_{1 \mathrm{p}}$ phase compound are very large, ${ }^{9)}$ the occurrence of slip deformation is hard to expect in the $\delta_{1 \mathrm{p}}$ phase. This is particularly the case for slip along the direction containing the $c$-axis component. However, slip along the $a$-axis direction may be possible if dislocation dissociation occurs so that the Burgers vector length for each of the relevant partial dislocations is sufficiently short. In single-crystal micropillar compression, we indeed observed the operation of slip along the $a$-axis

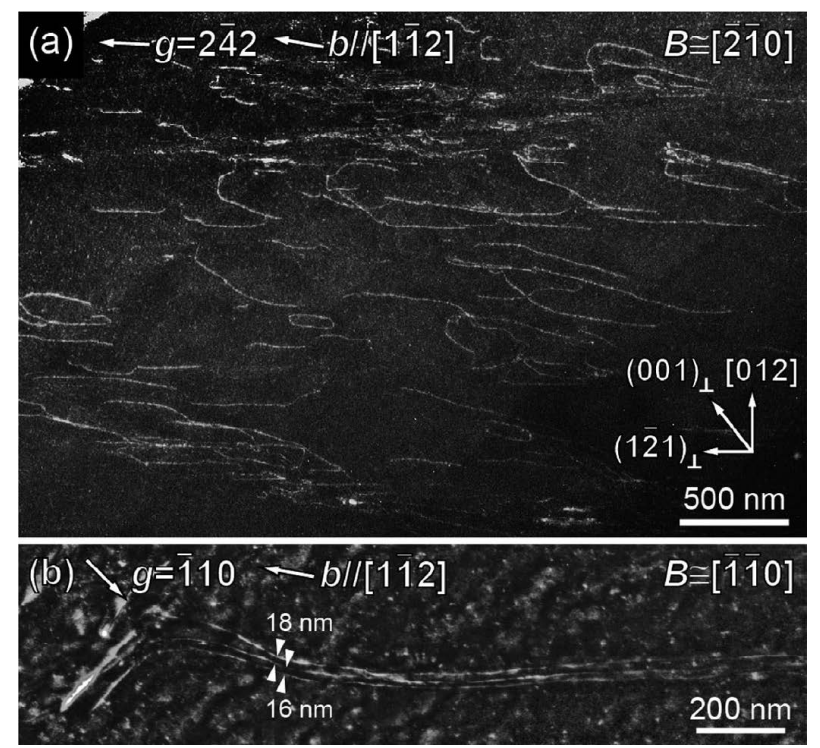

Fig. 12. (a) Dark-filed TEM image of a typical dislocation structure observed in a $\zeta$ crystallite embedded in the $\mathrm{Zn}$ matrix. ${ }^{19)}$ The image was taken with $\boldsymbol{g}$ (reflection vector) $=$ $2 \overline{4} 2$ and the beam direction $(\boldsymbol{B})$ was close to [ $\overline{2} \overline{10}$. (b) Weak-beam TEM image taken with $\boldsymbol{g}=\overline{1} 10$ to reveal the dissociation scheme of the dislocation with $\boldsymbol{b}=1 / 2\left[\begin{array}{ll}1 & \overline{1}\end{array} 2\right]$. direction on two different slip systems; $(0001)<2 \overline{1} 10>$ and $\{01 \overline{1} 0\}<2 \overline{1} \overline{1} 0>$. Of the two systems, the $(0001)<21 \overline{10}>$ basal slip system is the major slip system having a much lower CRSS value. The bulk CRSS values deduced in a similar way are $\sim 330 \mathrm{MPa}$ for $(0001)<21 \overline{1} 0>$ basal slip and $\sim 750 \mathrm{MPa}$ for $\{01 \overline{1} 0\}<2 \overline{1} \overline{0}>$ prism slip, indicating the operation of $(0001)<2110>$ basal slip in a much wider orientation range. Both basal and prism slip occurs involving the motion of many dislocations in avalanche on a single slip plane accompanied by a significantly large strain burst in the stress-strain curve, so that the specimen can be looked as if failed by slip plane failure after deformation. That is the reason why we mistakenly concluded in our previous study on polycrystals ${ }^{18)}$ that the $\delta_{\mathrm{lp}}$ phase does not plastically deform but fails in a brittle manner.

When the CRSS values of the easiest slip systems in the $\zeta$ and $\delta_{1 \mathrm{p}}$ phases are compared, the CRSS value for $(0001)<2110>$ slip in the $\delta_{1 \mathrm{p}}$ phase $(\sim 330 \mathrm{MPa})$ is obviously considerably higher than that for $\{110\}<112>$ slip in the $\zeta$ phase $(\sim 70 \mathrm{MPa})$. We believe that the difference in the linkage mode among Fe-centered $\mathrm{Zn}_{12}$ icosahedra, which are the common structural unit in the $\zeta$ and $\delta_{\text {lp }}$ phase compounds, is reflected to the difference in the CRSS values. While Fe-centered $\mathrm{Zn}_{12}$ icosahedra are linked to one another by vertex-sharing in the $\zeta$ phase, normal Fe-centered $Z_{12}$ icosahedra are linked to one another by face- and vertexsharing forming two types of basal slabs, which are bridged with each other by face-sharing with icosioctahedra in the $\delta_{1 \mathrm{p}}$ phase. Then, because of the incorporation of face-sharing in the linkage mode among Fe-centered $\mathrm{Zn}_{12}$ icosahedra in the $\delta_{1 \mathrm{p}}$ phase, Fe-centered $\mathrm{Zn}_{12}$ icosahedra have to be inevitably destroyed, breaking chemical bondings between Fe and $\mathrm{Zn}$ atoms in the icosahedra during slip, whatever the slip plane is. $(0001)<2110>$ slip inevitably destroy Fe-centered $\mathrm{Zn}_{12}$ icosahedra, breaking chemical bondings between Fe and $\mathrm{Zn}$ atoms in the icosahedra during slip. We believe that this is the reason for the higher CRSS value of $(0001)<21 \overline{1} 0 \geq$ slip in the $\delta_{\text {lp }}$ phase. This is also the case for $\{01 \overline{10}\}<21 \overline{10}>$ prism slip. Of significance to note, however, is that basal slip may occur along the slip plane where $\mathrm{Fe}-\mathrm{Zn}$ atomic bondings within the Fe-centered $\mathrm{Zn}_{12}$ icosahedra as well as $\mathrm{Zn}-\mathrm{Zn}$ atomic bondings in the $\mathrm{Zn}$-centered $\mathrm{Zn}_{16}$ icosioctahedra are broken, while prism slip needs to break much more $\mathrm{Fe}-\mathrm{Zn}$ atomic bondings within the Fe-centered $\mathrm{Zn}_{12}$ icosahedra. We believe that this is the reason for the higher CRSS value for prism slip than for basal slip.

\subsection{3. $\delta_{1 \mathrm{k}}$ Phase}

In view of the fact the $\delta_{1 \mathrm{k}}$ phase has a superlattice structure based on the $\delta_{1 \mathrm{p}}$ phase with a tripled periodicity along the $a$-axis direction of the $\delta_{1 \mathrm{p}}$ phase accompanied by one-dimensional disorder in the stacking along the $c$-axis direction, it is very hard to expect plasticity for this compound. Yet, we have recently observed plastic flow of the slip-plane-failure type in the $\delta_{1 \mathrm{k}}$ phase compound oriented favorably for $(0001)<2 \overline{1} 10>$ basal slip, as in the $\delta_{1 \mathrm{p}}$ phase compound. Significantly large strain burst is usually observed in the stress-strain curve, indicating the involvement of the motion of a large number of dislocations in avalanche. The bulk CRSS is deduced to be $\sim 450 \mathrm{MPa}$, which is much higher than that ( 330 MPa) for 
$(0001)<2 \overline{1} \overline{1} 0>$ slip in the $\delta_{\mathrm{lp}}$ phase. Since the atomic coordinates have yet to be deduced for the $\delta_{1 \mathrm{k}}$ phase compound, any detailed explanation for this in terms of the linkage mode of Fe-centered $\mathrm{Zn}_{12}$ icosahedra is difficult to make. In view of the tripled $a$-axis length, dislocations carrying slip along the $<2110>$ direction are expected to dissociate into a number of partial dislocations. This has yet to be clarified. The occurrence of $\{01 \overline{10}\}<21 \overline{1} 0>$ prism slip has also yet to be clarified for the $\delta_{1 \mathrm{k}}$ phase compound, although the multiplied $c$-axis dimension arising from one-dimensional stacking disorder is expected to make the operation of prism slip difficult. ${ }^{8)}$

\subsection{4. $\quad \Gamma_{1}$ Phase}

The $\Gamma_{1}$ phase compound has a cubic crystal structure with the face-centered lattice. The lattice constant is huge $(1.7989 \mathrm{~nm}){ }^{37)}$ amounting to about six times that of the underlying BCC lattice. Plastic flow is therefore expected to be difficult to occur in the $\Gamma_{1}$ phase. This is consistent with what is observed in experiment. Premature fracture occurs without showing any evidence of plasticity at a very high stress level usually exceeding to $1 \mathrm{GPa}$. The observed high (fracture) strength is understandable when referring to the characteristics of the crystal structure. Because of the increased $\mathrm{Fe}$ content, excess $\mathrm{Fe}$ atoms that cannot be accommodated in the central sites of Fe-centered icosahedra occupy vertices of some icosahedra together with $\mathrm{Zn}$ atoms forming $(\mathrm{Zn}, \mathrm{Fe})_{12}$ icosahedra in the $\Gamma_{1}$ phase. ${ }^{37)}$ Since these $(\mathrm{Zn}, \mathrm{Fe})_{12}$ icosahedra are connected to one another not only by vertex-sharing but also by face-sharing, many strong Fe$\mathrm{Zn}$ bondings have to be broken during slip deformation, in addition to breaking $\mathrm{Fe}-\mathrm{Zn}$ bondings within the Fe-centered $(\mathrm{Zn}, \mathrm{Fe})_{12}$ icosahedra.

\subsection{5. $\Gamma$ Phase}

The $\Gamma$ phase has been believed to be very brittle from experience in the industry that the problem called 'powdering' occurs more frequently when annealing is made excessively so that the Fe content, i.e., the volume fraction of the $\Gamma\left(\Gamma / \Gamma_{1}\right)$ phase in the coating layer is high. ${ }^{68-70)}$ This is understandable from the complex crystal structure of the $\Gamma$ phase compound with the body-centered cubic lattice and a large lattice constant $(0.898 \mathrm{~nm})$. However, we have found plastic flow in the $\Gamma$ phase compound in micropillar compression. ${ }^{18,25)}$ Two different slip systems, $\left.\{110\}<111>25\right)$ and $\{110\}<001>$, are identified with the $\{110\}<111>$ slip system being the major slip system having a much lower CRSS value. The bulk CRSS values deduced are $\sim 240 \mathrm{MPa}$ for $\{110\}<111>$ slip and $\sim 550 \mathrm{MPa}$ for $\{110\}<001>$ slip, indicating the operation of $\{110\}<111>$ slip in a much wider orientation range. The CRSS values for the two slip systems operative in the $\Gamma$ phase are a little smaller than those in the $\delta_{\text {lp }}$ phase. This may be due to the fact that the crystal structure of the $\Gamma$ phase cannot be regarded as that comprises with the structural unit of Fe-centered $\mathrm{Zn}_{12}$ and/ or $(\mathrm{Zn}, \mathrm{Fe})_{12}$ icosahedron anymore because of the increased Fe content that makes (1) Fe atoms to occupy not only the center of icosahedra but also the vertex sites of these icosahedra and (2) the triangle face sites to share icosahedra by face-sharing to be occupied by more Fe atoms. This means that in the course of plastic deformation, the $\Gamma$-phase com- pound behaves more or less as a general compound with a complex crystal structure, and the characteristic feature in the crystal structure to be described with packing of coordinated polyhedra (icosahedra) is not important to describe the plastic deformation behavior.

\subsection{Correlation of Plastic Behavior with Building Prin- ciple of Crystal Structure}

The variation of CRSS (for slip deformation), hardness and fracture toughness with intermetallics compounds in the $\mathrm{Fe}-\mathrm{Zn}$ system are illustrated in Figs. 13(a)-13(c), respectively. The CRSS values plotted in Fig. 13(a) are from our micropillar compression tests. ${ }^{19,68)}$ Plastic flow is observed for four intermetallics $\left(\zeta, \delta_{1 \mathrm{p}}, \delta_{\mathrm{lk}}\right.$ and $\Gamma$ ) except for $\Gamma_{1}$. Three intermetallics, $\zeta, \delta_{\mathrm{lp}}$ and $\Gamma$, have two operative slip systems. In the plot of the hardness values (Fig. 13(b)) taken from
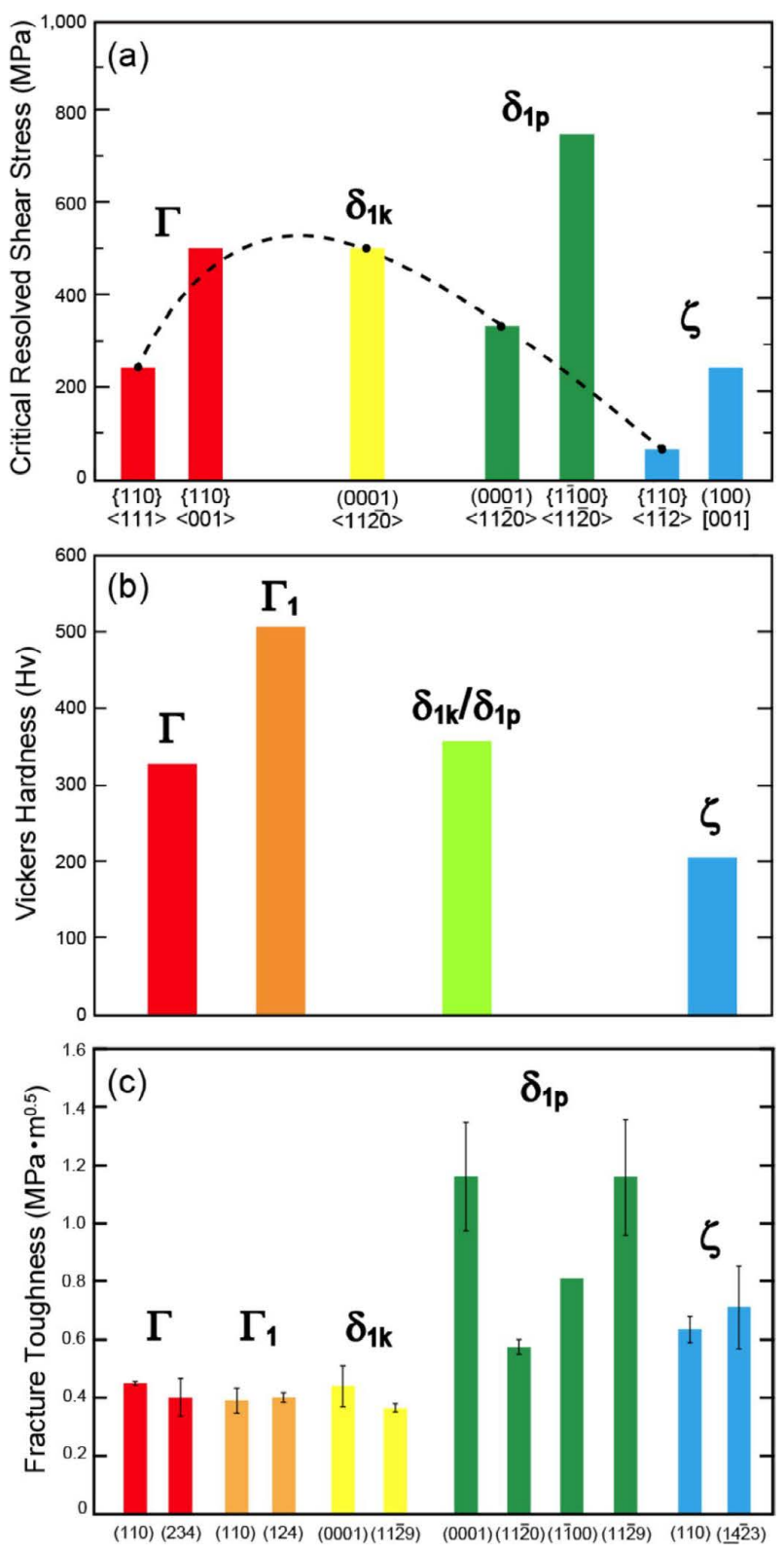

Fig. 13. Variation of (a) CRSS values, ${ }^{19)}$ (b) hardness ${ }^{71)}$ and (c) fracture toughness ${ }^{72}$ of the intermetallic compounds in the $\mathrm{Fe}-\mathrm{Zn}$ system . As the dashed curve in Fig. 13(a) indicates, the trend in the variation of the CRSS values for the major slip system with compounds is very similar to the hardness trend. (Online version in color.) 
Ref. 71, the value for the $\delta_{1}$ phase is plotted without differentiating $\delta_{1 \mathrm{p}}$ and $\delta_{1 \mathrm{k}}$. The fracture toughness values plotted in Fig. 13(c) are from our microbeam bending tests, whose results as well as experimental procedures are described in detail in a separate paper $^{72)}$ in this special issue. If we take the CRSS value for the major slip system (with the lower CRSS value) for each of the four intermetallics, the trend for CRSS values (dashed curve in Fig. 13(a)) is surprisingly very similar to the hardness trend explored a long time ago by Bastin et al. ${ }^{71)}$ (Fig. 13(b)). This may indicates that the hardness value also reflects the variation of chemical bonding in the compounds, as described in the following.

The bonding between $\mathrm{Fe}$ and $\mathrm{Zn}$ atoms is so strong that slip deformation occurs at a low stress level if any of Fe-centered $\mathrm{Zn}_{12}$ icosahedra are not destroyed during slip deformation. This is possible for the $\zeta$ phase compound, since in the crystal structure, Fe-centered $\mathrm{Zn}_{12}$ icosahedra are linked to one another by vertex-sharing to form a chain of $\mathrm{Zn}_{12}$ icosahedra along the $c$-axis. So, the $\{110\}$ plane is selected so as not to destroy the vertex-shared $c$-axis chains of Fe-centered $\mathrm{Zn}_{12}$ icosahedra, and the lowest CRSS value was observed for the corresponding slip. The CRSS value increases for the $\delta_{\mathrm{lp}}$ phase, in which normal Fe-centered $\mathrm{Zn}_{12}$ icosahedra are linked to one another by face- and vertex-sharing forming two types of basal slabs, which are bridged with each other by face-sharing with icosioctahedra. Because of the incorporation of face-sharing in the linkage mode among Fe-centered $\mathrm{Zn}_{12}$ icosahedra in the $\delta_{1 \mathrm{p}}$ phase, Fe-centered $\mathrm{Zn}_{12}$ icosahedra have to be inevitably destroyed, breaking chemical bondings between $\mathrm{Fe}$ and $\mathrm{Zn}$ atoms in the icosahedra during slip, whatever the slip plane is. This is the reason for the higher CRSS value of $(0001)<2110>$ slip in the $\delta_{\mathrm{lp}}$ phase. However if the Fe content increases considerably as in the $\Gamma$ phase so that $\mathrm{Fe}$ atoms occupy not only the center of icosahedra but also the vertex sites of these icosahedra to form Fe-centered $(\mathrm{Zn}, \mathrm{Fe})_{12}$ icosahedra and the triangle face sites to share icosahedra by face-sharing are occupied mostly by $\mathrm{Fe}$ atoms, the description of the crystal structure by the packing of coordinated polyhedra becomes less important and the crystal structure can be better described simply as a general compound with a complex crystal structure. Then, the characteristic feature in the crystal structure to be described with packing of coordinated polyhedra (icosahedra) is not important to describe the plastic deformation behavior. We believe this is the reason for the smaller CRSS value in the $\Gamma$ phase than in the $\delta_{1 \mathrm{p}}$ phase.

Of importance to notice is that the $\delta_{\mathrm{lp}}$ phase, the major constituent phase in the coating layer of GA steels in practical use, possesses plasticity as well as the fracture toughness value which is the highest among the five intermetallics (Fig. 13(c)) ${ }^{72)}$ This means that the microstructure of the coating layer with the $\delta_{1 \mathrm{p}}$ phase being the major (thickest) constituent phase is indeed a very reasonable choice of microstructure. However, the CRSS value (strength) of the $\delta_{\mathrm{lp}}$ phase seems to be a bit too high when compared with those of the other intermetallics in the $\mathrm{Fe}-\mathrm{Zn}$ system. If the strength of the $\delta_{1 \mathrm{p}}$ phase is reduced, we may expect better formability of GA steels without being bothered by the problem called 'powdering'. This may be achieved by changing the crystal structure of the $\delta_{\mathrm{lp}}$ phase, for example by alloying, so that the extent of vertex-sharing (instead of face-sharing) among Fe-centered $\mathrm{Zn}_{12}$ icosahedra is increased as in the case of the $\zeta$ phase, or that the crystal structure becomes more complicated to behave as a general compound as in the case of the $\Gamma$ phase.

\section{Conclusions}

(1) There is a building principle of the crystal structures for intermetallics of the Fe- Zn system. The crystal structures of all the $\mathrm{Fe}-\mathrm{Zn}$ intermetallics can be best understood by considering the packing of coordinated polyhedra with the common structural unit being the $\mathrm{Zn}_{12}$ and/or $(\mathrm{Zn}, \mathrm{Fe})_{12}$ icosahedron whose central site is exclusively occupied by an $\mathrm{Fe}$ atom. When the $\mathrm{Fe}$ content is increased so that all $\mathrm{Fe}$ atoms cannot be accommodated in the central sites of these icosahedra, these excess Fe atoms occupy vertices of some icosahedra together with $\mathrm{Zn}$ atoms forming $(\mathrm{Zn}, \mathrm{Fe})_{12}$ icosahedron. As the $\mathrm{Fe}$ content of the $\mathrm{Fe}-\mathrm{Zn}$ intermetallics increases, (i) the linkage geometry among the Fe-centered icosahedra changes from vertex-sharing to face-sharing, (ii) the atoms occupancy (either $\mathrm{Zn}$ or $\mathrm{Fe}$ atoms) at the face-sharing sites changes from exclusive occupancy by $\mathrm{Zn}$ atoms to mixed occupancy by $\mathrm{Zn}$ and $\mathrm{Fe}$ atoms and to exclusive occupancy by Fe atoms, and (iii) the fraction of isolated $\mathrm{Zn}$ atoms decreases.

(2) Plastic deformation occurs in four intermetallic compounds, $\Gamma, \delta_{1 \mathrm{p}}, \delta_{1 \mathrm{k}}$ and $\zeta$ phases. The variation of CRSS values with intermetallics can be well correlated with the building principle of the crystal structures described above. The selection of slip planes is closely related to the arrangement of Fe-centered $Z_{12}$ icosahedra. The slip plane is determined so as not to break any $\mathrm{Fe}-\mathrm{Zn}$ atomic bondings within the Fe-centered $\mathrm{Zn}_{12}$ icosahedra during slip. This is particularly the case for the intermetallics with a lesser Fe content, the $\zeta$ phase, in which the linkage mode among Fecentered $\mathrm{Zn}_{12}$ icosahedra is only vertex-sharing. But, once face-sharing occurs in the linkage mode among Fe-centered $\mathrm{Zn}_{12}$ icosahedra as in the $\delta_{\mathrm{lp}}$ phase, some $\mathrm{Fe}-\mathrm{Zn}$ atomic bondings within the Fe-centered $\mathrm{Zn}_{12}$ icosahedra are inevitably broken during slip, resulting in the higher CRSS value.

\section{Acknowledgements}

This work was supported by JSPS KAKENHI grant numbers 16H04516, 16K14373, 16K14415 and 15H02300, and the Elements Strategy Initiative for Structural Materials (ESISM) from the Ministry of Education, Culture, Sports, Science and Technology (MEXT) of Japan, and in part by Advanced Low Carbon Technology Research and Development Program (ALCA) from the Japan Science and Technology Agency (JST). This work was also supported by Innovative Program for Advanced Technology as well as 20th and 24th Research Promotion Grants from the Iron and Steel Institute of Japan (ISIJ). The synchrotron radiation experiments were performed at the BL02B1 of SPring- 8 with the approval of the Japan Synchrotron Radiation Research Institute (JASRI) (Proposal Nos. 2014B1228, 2015A1468, 2016B1096 and 2017A1243). We wish to thank Dr. K. Sugimoto for their assistance at the BL02B1 of SPring-8. 


\section{REFERENCES}

1) M. F. Shi, G. M. Smith, M. Moore and D. J. Meuleman: Zinc-based Steel Coating Systems: Metallurgy and Performance, ed. by G. Krauss and D. K. Matlock, TMS, Warrendale, PA, (1990), 387.

2) A. R. Marder: Prog. Mater. Sci., 45 (2000), 191.

3) S. M. A. Shibli, B. N. Meena and R. Remya: Surf. Coat. Technol., 262 (2015), 210.

4) O. Kubaschewski: Iron - Binary Phase Diagrams, Springer-Verlage, Berlin, (1982), 172

5) X. P. Su, N. Y. Tang and J. M. Toguri: J. Alloy. Compd., 325 (2001), 129.

6) J. Nakano, D. V. Malakhov and G. R. Purdy: Calphad, 29 (2005), 276.

7) R. Kainuma and K. Ishida: Tetsu-to-Hagané, 91 (2005), 349.

8) N. L. Okamoto, A. Yasuhara and H. Inui: Acta Mater., 81 (2014), 345.

9) N. L. Okamoto, K. Tanaka, A. Yasuhara and H. Inui: Acta Crystallogr. $B, 70$ (2014), 275.

10) P. Villars: Pearson's Handbook: Crystallographic Data for Intermetallic Phases, ASM International, Materials Park, OH, (1997), 2248.

11) K. Han, I. Ohnuma, K. Okuda and R. Kainuma: J. Alloy. Compd., 737 (2018), 490.

12) A. Iost and J. Foct: J. Mater. Sci. Lett., 12 (1993), 1340.

13) C. Kato, H. Koumura, Y. Uesugi and K. Mochizuki: TMS Annual Meeting, The Physical Metallurgy of Zinc Coated Steel, ed. by A. R. Marder, TMS, Warrendale, PA, (1994), 241.

14) M. H. Hong and H. Saka: Philos. Mag. A, 74 (1996), 509.

15) M. H. Hong and H. Saka: Acta Mater., 45 (1997), 4225.

16) M. H. Hong and H. Saka: Scr. Mater., 36 (1997), 1423.

17) A. T. Alpas and J. Inagaki: ISIJ Int., 40 (2000), 172.

18) N. L. Okamoto, D. Kashioka, M. Inomoto, H. Inui, H. Takebayashi and S. Yamaguchi: Scr. Mater., 69 (2013), 307.

19) N. L. Okamoto, M. Inomoto, H. Adachi, H. Takebayashi and H. Inui: Acta Mater., 65 (2014), 229.

20) J. Inoue, S. Miwa and T. Koseki: Tetsu-to-Hagané, 100 (2014), 383.

21) J. Inoue, S. Miwa and T. Koseki: Tetsu-to-Hagané, 100 (2014), 390

22) S. Lee, M. Joun, D. Kim and J. Lee: J. Mech. Sci. Technol., 30 (2016), 3313

23) U. Roy and C. Ghosh: Ironmaking Steelmaking, 43 (2016), 465

24) M. Inomoto, N. L. Okamoto and H. Inui: Mater. Res. Soc. Symp. Proc., 1516 (2013), 157.

25) M. Inomoto, N. L. Okamoto and H. Inui: Adv. Mater. Res., 922 (2014), 264.

26) A. J. Bradley and J. Thewlis: Proc. R. Soc. Lond. A, 112 (1926), 678

27) P. J. Brown: Acta Crystallogr., 15 (1962), 608.

28) A. Johansson, H. Ljung and S. Westman: Acta Chem. Scand., 22 (1968), 2743.

29) J. K. Brandon, R. Y. Brizard, P. C. Chieh, R. K. Mcmillan and W. B. Pearson: Acta Crystallogr. B, 30 (1974), 1412

30) P. J. Gellings, E. Willemdebree and G. Gierman: Z. Metallkd., 70 (1979), 312.

31) P. J. Gellings, E. Willemdebree and G. Gierman: Z. Metallkd., 70 (1979), 315.

32) A. S. Koster and J. C. Schoone: Acta Crystallogr. B, 37 (1981), 1905

33) C. H. E. Belin and R. C. H. Belin: J. Solid State Chem., 151 (2000), 85.

34) R. Belin, M. Tillard and L. Monconduit: Acta Crystallogr. C, 56 (2000), 267.

35) N. L. Okamoto, A. Yasuhara, K. Tanaka and H. Inui: Mater. Res. Soc. Symp. Proc., 1760 (2015), DOI: 10.1557/opl.2015.10.

36) N. L. Okamoto, H. Inui, A. Yasuhara and S. Yamaguchi: J. Alloy. Compd., 644 (2015), 287.

37) N. L. Okamoto, M. Inomoto, H. Takebayashi and H. Inui: J. Alloy.
Compd., 732 (2018), 52.

38) N. L. Okamoto, D. Kashioka and H. Inui: Mater. Res. Soc. Symp. Proc., 1516 (2013), 283.

39) F. C. Frank and J. S. Kasper: Acta Crystallogr., 11 (1958), 184.

40) F. C. Frank and J. S. Kasper: Acta Crystallogr., 12 (1959), 483.

41) International Tables for Crystallography, Vol. A: Space-Group Symmetry, 5th ed., ed. by T. Hahn, Springer, Dordrecht, The Netherlands, (2005), 38.

42) M. A. Ghoniem and K. Lohberg: Metall, 26 (1972), 1026.

$43)$ R. Kainuma and K. Ishida: ISIJ Int., 47 (2007), 740.

44) K. Dornberger-Schiff: Acta Crystallogr., 9 (1956), 593

45) S. Durovic: Acta Crystallogr. B, 30 (1974), 76

46) R. F. Berger, S. Lee, J. Johnson, B. Nebgen, F. Sha and J. Q. Xu: Chem. Eur. J., 14 (2008), 3908.

47) J. Dshemuchadse, D. Y. Jung and W. Steurer: Acta Crystallogr. B, 67 (2011), 269

48) A. A. Pankova, V. A. Blatov, G. D. Ilyushin and D. M. Proserpio: Inorg. Chem., 52 (2013), 13094.

49) J. S. Yu, J. L. Liu, W. M. Zhou, J. X. Zhang and J. S. Wu: Mater. Des., 28 (2007), 249.

50) W. W. Xie, J. Liu, V. Pecharsky and G. J. Miller: Z. Anorg. Allg. Chem., 641 (2015), 270.

51) J. C. Verplanke, G. F. Bastin and F. J. J. Vanloo: Krist. Tech., 14 (1979), 445

52) K.-K. Wang, G.-L. You, L. Chang, D. Gan and L.-J. Chiang: Mater. Charact., 107 (2015), 23.

53) W. Koster and T. Godecke: Z. Metallkd., 61 (1970), 649.

54) Y. Adachi and K. Kamei: Acta Metall. Mater., 43 (1995), 3189.

55) F. H. Kao, W. C. Li, C. Y. Chen, C. Y. Huang, J. R. Yang and S. H. Wang: Mater. Sci. Eng., 499 (2009), 45.

56) L. Cho, M. S. Kim, Y. H. Kim and B. C. De Cooman: Metall. Mater. Trans. A, 44 (2013), 5081.

57) R. Peierls: Proc. Phys. Soc., 52 (1940), 34

58) F. R. N. Nabarro: Proc. Phys. Soc., 59 (1947), 256.

59) D. M. Dimiduk, M. D. Uchic and T. A. Parthasarathy: Acta Mater., 53 (2005), 4065.

60) M. D. Uchic, D. M. Dimiduk, J. N. Florando and W. D. Nix: Science, 305 (2004), 986.

61) M. D. Uchic, P. A. Shade and D. M. Dimiduk: Annu. Rev. Mater. Res., 39 (2009), 361

62) J. R. Greer and J. T. M. De Hosson: Prog. Mater. Sci., 56 (2011), 654.

$63)$ Z. H. M. T. Chen, N. L. Okamoto, M. Demura and H. Inui: Scr. Mater., 121 (2016), 28

64) N. L. Okamoto, S. Fujimoto, Y. Kambara, M. Kawamura, Z. M. T. Chen, H. Matsunoshita, K. Tanaka, H. Inui and E. P. George: Sci. Rep., 6 (2016), 35863.

65) N. L. Okamoto, D. Kashioka, T. Hirato and H. Inui: Int. J. Plast., 56 (2014), 173

66) N. L. Okamoto, D. Kashioka and H. Inui: Mater. Res. Soc. Symp. Proc., 1516 (2013), DOI: 10.1557/opl.2013.559.

67) J. Y. Zhang, K. Kishida and H. Inui: Int. J. Plast., 92 (2017), 45

68) C. E. Jordan and A. R. Marder: Metall. Mater. Trans. A, 25 (1994), 937.

69) C. W. Cheng, V. Rangarajan, L. Franks and J. L'Ecuyer: 2nd Int. Conf. on Zinc and Zinc Alloy Coated Steel Sheet (GALVATECH '92), Stahl and Eisen, Düsseldorf, (1992), 122

70) Y. Tokunaga, M. Yamada and T. Hada: Tetsu-to-Hagané, 72 (1986), 997.

71) G. F. Bastin, F. J. J. Vanloo and G. D. Rieck: Z. Metallkd., 65 (1974), 656.

72) N. L. Okamoto, S. Michishita, Y. Hashizume and H. Inui: ISIJ Int., 58 (2018), 1569

73) R. Kohlhaas, P. Dunner and N. Schmitzp: Z. Angew. Phys., 23 (1967), 245 . 